\title{
Optimization of WEDM for precise machining of novel developed Al6061-7.5\% SiC squeeze-casted composite
}

\author{
Kashif Ishfaq ${ }^{1}$ - Saqib Anwar ${ }^{2} \cdot$ Muhammad Asad Ali $^{1} \cdot$ Muhammad Huzaifa Raza $^{3}$. Muhammad Umar Farooq ${ }^{1}$. \\ Shafiq Ahmad ${ }^{2} \cdot$ Catalin I. Pruncu $^{4,5}$ (I) Mustafa Saleh ${ }^{2} \cdot$ Bashir Salah $^{2}$
}

Received: 7 July 2020 / Accepted: 5 October 2020 / Published online: 21 October 2020

(C) The Author(s) 2020

\begin{abstract}
The emerging demands of industry for developing the novel materials with superior mechanical properties have successfully resulted in the development of distinct materials such as Al-matrix composites. Among these composites, newly developed Al6061-7.5\% $\mathrm{SiC}$ holds promising mechanical characteristics. But, the $\mathrm{SiC}$ reinforcement in the Al-matrix makes the machining of this composite challenging, thus posing a serious concern regarding its effective utilization. In this research, high-speed wire electric discharge machining (WEDM) was employed for the precise machining of a squeeze casted Al6061-7.5\% SiC composite. The cutting performance of the WEDM was assessed in terms of roughness $\left(S_{\mathrm{R}}\right)$, cutting rate $\left(C_{\mathrm{s}}\right)$ and kerf width $\left(K_{\mathrm{W}}\right)$. Experimentation was performed according to the response surface methodology. The experimental findings were thoroughly investigated using statistical, optical and scanning electron microscopic (SEM) analyses. It has been revealed that the voltage is most influential/contributing parameter (having a percentage contribution of 25\%) for controlling the $S_{\mathrm{R}}$ during WEDM of Al6061-7.5\% SiC composite, whereas for the $C_{\mathrm{S}}$ and $K_{\mathrm{W}}$, pulse and current are the major contributing control variables with percentage contributions of $90 \%$ and $84 \%$, respectively. At low magnitude of both current and voltages, the surface quality is improved up to $33.3 \%$. The SEM and optical microscopic evidences reveal shallow craters, small size melt re-deposits and micro globules on the machined surface at lower settings of both the said variables. Contrarily, for achieving higher cutting speed, high values of current and voltage along with low pulse are deemed essential. In case of $K_{\mathrm{W}}$, low magnitude of current and voltage along with smaller pulse yields $20 \%$ reduction in the kerf width. The analyses revealed the conflicting nature of the studied output responses $\left(S_{\mathrm{R}}, C_{\mathrm{s}}\right.$ and $\left.K_{\mathrm{W}}\right)$. Therefore, multi-objective genetic algorithm (MOGA) was used to find a parametric combination. The best combination of WEDM input parameters found is current $=3 \mathrm{~A}$, voltage $=84.999 \mathrm{~V}$ and pulse $=10 \mathrm{mu}$. This combination gives a minimum $S_{\mathrm{R}}$ of $5.775 \mu \mathrm{m}$ with a $K_{\mathrm{W}}$ of $0.3111 \mathrm{~mm}$ at a $C_{\mathrm{S}}$ of $5.885 \mathrm{~mm} / \mathrm{min}$. The suitability of the MOGA-proposed parametric combination was witnessed through confirmation trials. Furthermore, the parametric effects have also been mathematically quantified with respect to the defined machinability parameters.
\end{abstract}

Keywords WEDM $\cdot$ Roughness $\cdot$ Cutting rate $\cdot$ Kerf width $\cdot$ Al6061-7.5\% SiC $\cdot$ MOGA $\cdot$ SEM $\cdot$ Optical microscopic

Catalin I. Pruncu

catalin.pruncu@strath.ac.uk; c.pruncu@imperial.ac.uk

Kashif Ishfaq

kashif.ishfaq@uet.edu.pk

Saqib Anwar

sanwar@ksu.edu.sa

Muhammad Asad Ali

asad.ali@uet.edu.pk

Muhammad Huzaifa Raza

huzaifa@connect.hku.hk

Muhammad Umar Farooq

muf@uet.edu.pk

Shafiq Ahmad

ashafiq@ksu.edu.sa
Mustafa Saleh

msaleh3@ksu.edu.sa

Bashir Salah

bsalah@ksu.edu.sa

1 Department of Industrial and Manufacturing Engineering, University of Engineering and Technology, Lahore 54890, Pakistan

2 Industrial Engineering Department, College of Engineering, King Saud University, P.O. Box 800, Riyadh 11421, Saudi Arabia

3 Department of Industrial and Manufacturing Systems Engineering, The University of Hong Kong, Pok Fu Lam, Hong Kong

4 Design, Manufacturing \& Engineering Management, University of Strathclyde, Glasgow G1 1XJ, Scotland, UK

5 Department of Mechanical Engineering, Imperial College London, London SW7 2AZ, UK 


\section{Introduction}

Metal matrix composites (MMCs) have emerged as a valuable choice for aerospace, automobile and defense industry as they offer the desired blend of mechanical properties $[1,2]$. The MMC composites are prepared by embedding various types of reinforcements in the substrate metal alloys during various fabrication methods [3]. Aluminum matrix composites (AMCs) are one of the best representations of MMCs, due to their high strength, good toughness, low thermal expansion, better abrasion and wear resistance and being lightweight. These prominent characteristics have made this class of materials found in a wide range of applications in aerospace, defense and automobile sectors [4]. It is pertinent to mention that reinforcements in AMCs hold a pivotal role in governing the aforementioned characteristics. The selection of the appropriate concentration of the reinforcements is therefore essential to ensure better mechanical attributes of the resulting composite. For instance, the reinforcements are introduced to enhance the strength of the material, but a high quantity of reinforcement is a source of significant reduction of resulting composite's ductility [5]. Composite materials consist of discrete reinforcement particles that are scattered in a continuous phase of the substrate metal. The unique attributes of the reinforcement particles are extracted by base metal to yield an aluminum matrix composite (AMC) of superior mechanical properties [6]. The AMCs are generally prepared by powder metallurgy in situ, metal infiltration and stir casting processes [7]. Mostly, the silicon carbide $(\mathrm{SiC})$ and alumina $\left(\mathrm{Al}_{2} \mathrm{O}_{3}\right)$ are used as reinforcement in AMCs. SiC particles alter the microstructural attributes of AMCs and elevate their strength [8].

$\mathrm{AMC}$ in which particulate $\mathrm{SiC}$ is reinforced such as Al6061/SiC has numerous applications in aerospace and automotive sector due to its improved mechanical properties [9]. However, the use of AMC offers a variety of benefits in terms of superior mechanical attributes; their tremendous hardness and reinforced strength have made their cutting difficult via conventional machining processes. Hardness is not an issue for the non-conventional machining processes, especially for electric discharge machining. Wire electric discharge machining (WEDM) is a viable option for the cutting of these types of materials, which are not only difficult-to-cut; rather, their intended applications require the formation of intricate profiles [10]. Moreover, less burr formation and no residual stresses during WEDM are the added advantages that further highlight its supremacy/acceptability. With respect to equipment used for performing WEDM, two variants are available: (i) slow speed and (ii) high-speed cutting equipment [11]. In the former, usually, brass wire is used as an electrode that is consistently consumed and cannot be recycled, but in the latter one, a molybdenum wire electrode is employed. Molybdenum wire is recyclable and provides a faster cutting rate, that is why it is commonly used in industry [12]. Therefore, a molybdenum wire of $0.18 \mathrm{~mm}$ diameter is used in the present research.

In WEDM, the workpiece material is removed by the thermo-electric spark erosion process [13]. A thin wire of brass, tungsten or molybdenum (diameter varies from 0.05 to $0.3 \mathrm{~mm}$ ) is generally used as an electrode for producing the required profiles in the target workpiece. Both the electrode and the workpiece are submerged into the dielectric fluid. As the current passes through the wire electrode, it creates a series of repetitive sparking in the workpiece-electrode gap. These series of sparks cause intense localized heating, which raises the temperature on the interface region up to $12,000{ }^{\circ} \mathrm{C}$. The surface of the workpiece exposed to the wire electrode is machined due to localized melting and vaporization, which is the result of intense heating. The melted debris thus formed during cutting are removed by the circulating dielectric fluid [14]. Because of the excellent cutting capability of the WEDM process for producing complex and delicate shapes, it has wide applications in various industries like dies and molds, aerospace, surgical and automobile [15].

In WEDM, the cutting potential is commonly assessed in terms of machining characteristics such as cutting rate/speed $\left(C_{\mathrm{S}}\right)$, kerf width $\left(K_{\mathrm{W}}\right)$, and surface roughness $\left(S_{\mathrm{R}}\right)$ [10]. Numerous researches have been conducted in the past considering the said response attributes during WEDM of a variety of materials. For instance, Gopalakannan et al. [16] investigated the influence of current $(I)$, voltage $(V)$ and pulse on-time $\left(T_{\mathrm{on}}\right)$ on the cutting rate and surface roughness while machining $\mathrm{Al}$ 7075-B4C. Experimental results revealed that the increase in above-mentioned control parameters yields a higher cutting rate and poor surface finish. The same trend was witnessed by [17] during WEDM of armour materials. It was also observed that a higher value of current causes a frequent wire breakage during cutting. Chaudhari et al. [18] worked on surface analysis of shape memory alloy by WEDM. They found that defect-free and better surface finish obtained at optimized values of current, pulse on and off time. Mandal et al. [19] enhanced the surface integrity of super alloy (Nimonic C 263) generated by WEDM. In another research conducted on WEDM of AMC (A413- $\left.\mathrm{B}_{4} \mathrm{C}\right)$, it was claimed that voltage and feed rate were the main driving control variables for cutting rate, $K_{\mathrm{W}}$ and $S_{\mathrm{R}}$ [20]. Cutting rate was also noted to have a direct dependence on the power used during WEDM of high-strength low alloy (HSLA) steel. It was narrated that the larger the magnitude of the power, the higher would be the $C_{\mathrm{S}}$ [12]. Abbasi et al. [21] reported that surface roughness of high-strength low alloy (HSLA) steel has been drastically affected by pulse on time, power (current) and pulse (spark gap) during WEDM. Nawaz et al. [22] investigated the WEDM machining characteristics $\left(S_{\mathrm{R}}, K_{\mathrm{W}}\right.$, cutting rate) of $\mathrm{DC}_{53}$ die steel. They reported that current intensity significantly affecting the $S_{\mathrm{R}}$ and $K_{\mathrm{W}}$, while $T_{\text {on }}$ has vital 
impact on cutting rate. Suresh and Sudhakara [23] examine the WEDM parametric effects on AA7075/nano-SiC composite. They observed that voltage was the key parameter that influences the cutting rate, whereas pulse duration was prominently affecting the surface roughness. Rao and Krishna [24] examined the machining performance characteristics of A17075/SiC during the WEDM. They observed that $T_{\text {on }}$ significantly impacting the $S_{\mathrm{R}}$. Dey and Pandey [10] investigated the WEDM performance measures for AMCs (AA6061/ cenosphere). They observed that at a higher value of current and pulse on time, high instantaneous energy was released that caused the enhanced melting of the base metal matrix and deteriorated the machined surface. Prakash et al. [25] found that voltage $(66.27 \%)$ and pulse on time $(18.74 \%)$ prominently influenced the cutting rate during the WEDM of 356/B4C/ fly ash composite. In another research work [26], it was established that higher current leads to high thermal melting of material by generating large size crater on the machined surface of AMC that reduced the surface quality. Moreover, at higher pulse duration, intense sparking occurs, which caused poor surface quality. Karabulut et al. [27] investigated the effects of peak current and voltage on $S_{\mathrm{R}}$ during the WEDM of AA6061-B ${ }_{4} \mathrm{C}$ composite. They observed that $S_{\mathrm{R}}$ increased with increment in peak current $(10 \mathrm{~A}$ to $16 \mathrm{~A})$ and voltage $(68 \mathrm{~V}$ to $80 \mathrm{~V})$.

Researchers have also tested various statistical and mathematical techniques for the analysis and modelling of the defined responses in WEDM. Tarang et al. [28] applied simulated annealing algorithm for the optimization of input parameters (open voltage, discharge capacitance and revolving speed) for response measures $\left(C_{\mathrm{S}}\right.$ and $\left.S_{\mathrm{R}}\right)$. Geng et al. [29] employed response surface methodology (RSM) for experimental design, results' analysis and optimization of input variables. Their results revealed that current and gap voltage were the most effective input parameters for cutting rate $\left(C_{\mathrm{S}}\right)$. In another study conducted on WEDM of HSLA, a factorial design was used to evaluate the effect of input variables on the response attributes including $C_{\mathrm{S}}$ and percentage dimensional deviation and parametric significance was examined with the help of analysis of variance (ANOVA) [30]. Tosun et al. [31] applied the Taguchi design to optimize the input parameters for $C_{\mathrm{S}}$ and $K_{\mathrm{W}}$ with a minimum number of experiments. Tahir et al. [32] used a fractional factorial design for modeling and analysis of white layer thickness, micro-hardness and wire material infusion.

In recent years, the utility of hybrid techniques is seeking more attention due to their capability of optimizing complex multi-objective problems. Such techniques are widely used in manufacturing processes, which are specifically carried out in uncertain and complex situations. Lin et al. [33] employed a grey-fuzzy-logic hybrid technique for the multi-response optimization in electric discharge machining. Soepangkat and Pramujati [34] carried out the optimization of electric discharge machining using integrated grey relational analysis (GRA) and fuzzy logic to minimize white layer thickness and surface roughness. Sanchez et al. [35] used the computer simulation for the WEDM taper cutting, which yields efficient results in terms of machining accuracy. Dewangan et al. [36] employed hybrid fuzzy and TOPSIS techniques for surface quality and dimensional accuracy. Jafarian [37] used hybrid non-dominated sorting genetic algorithm and artificial neural network for the optimization of the process parameters of the electric discharge machining process. According to Biswas et al. [38], a multi-objective genetic algorithm (MOGA) is a very useful optimization approach for conflicting responses such as surface roughness and cutting speed. Thus, it is conceivable to obtain a diverse set of solutions with more variables that can be optimized simultaneously [39].

The published literature confirms that the use of AMCs offers superior mechanical properties in its end-use applications. However, its machining challenge is the major obstacle for an effective integration in industrial use. In this research, the cutting challenges associated to the WEDM of newly developed AMC (A16061-7.5\% SiC) were systematically investigated. It is pertinent to mention that very limited literature reported discussion about the electric discharge cutting issues of the selected material. Furthermore, a multi-objective optimization approach was implemented to solve the conflicting nature responses produced by cutting speed, surface roughness and kerf width, causing the individually optimized settings to not serve the purpose. From industrial perspective, the optimum combination is essential to warrant the obtaining of best balance amongst the defined responses. The multi-objective optimization is a robust tool which can provide the best solution, but this was not yet explored systematically so far. Therefore, in this research, a hybrid optimization approach, i.e. multi-objective genetic algorithm (MOGA), was employed for the development of optimal settings. The proposed settings result in simultaneous optimization of all the conflicting response attributes. Experimentation was planned according to response surface methodology using Box-Behnken design considering the current, voltage and pulse as control variables. The results of experimentation have been deeply analyzed using various statistical, optical and scanning electron microscopic analyses. Moreover, the formulation of mathematical models for accurate prediction of the defined responses has also been done. An optimal parametric setting was achieved using MOGA optimization methodology that yields optimum values of all the conflicting response characteristics.

\section{Materials and methods}

This research work has been organized systematically to evade any inconsistency. The detailed research methodology 
of the current work consists of different steps that are presented in Fig. 1 After examining the experimental needs, the first stage was divided into two segments: (1) identification of input parameters and their ranges and (2) material selection. After the selection of casting material and reinforced particles, $\mathrm{AMC}$ was prepared by squeeze casting. When the workpiece was ready after casting, trial runs were performed on the wire electric discharge machine in the second stage using the molybdenum wire electrode. While in the third stage, the experimental design matrix was finalized, experimentation was completed as per DOE. In the fourth stage, testing of machined samples for $S_{\mathrm{R}}, K_{\mathrm{W}}$ and $C_{\mathrm{S}}$ was done. In the fifth stage, results and analysis and model validation were discussed. In the sixth stage, multi-objective optimization was employed using MOGA. Finally, conclusions were drawn from RSM and MOGA-based results.

For the present study, aluminum alloy Al-6061 has been selected as the base metal for the preparation of AMC by squeeze casting [40]. Before the preparation of AMC, the chemical composition of base metal (Al-6061) was verified by optical emission spectroscopy and presented in Table 1. In this study, $7.5 \mathrm{wt} \%$ silicon carbide ( $\mathrm{SiC}$ ) particles of average size of $37 \mu \mathrm{m}$ were used as reinforcement in AMC. Squeeze casting setup used for the preparation of AMC in this research has been displayed in Fig. 2. The setup comprised a furnace for the preparation of melt of the base metal, a mechanical stirrer for the mixing of $\mathrm{SiC}$ particles in the melt, a metallic die in which mixture of base metal and $\mathrm{SiC}$ particles was poured and a hydraulic press to squeeze the melt. The melt of Al-6061 was prepared in an electric resistance furnace at $800{ }^{\circ} \mathrm{C}$, and at the same time, $\mathrm{SiC}$ particles were preheated at $1000{ }^{\circ} \mathrm{C}$ for $3 \mathrm{~h}$ to improved wettability. A double stirring mechanism was opted for the uniform dispersion of SiC particles in the melt. The mixture of the melt and $\mathrm{SiC}$ particles was kept under high pressure of $120 \mathrm{MPa}$ for $2 \mathrm{~min}$. Upon solidification, a cylindrical billet of average diameter $56 \mathrm{~mm}$ and length $140 \mathrm{~mm}$ was extracted from the metallic die. The cylindrical billet of AMC was cut into thin slices of $10 \mathrm{~mm}$ thickness for experimentation purpose. Prepared specimens were solution heat-treated at $530^{\circ} \mathrm{C}$ for $4 \mathrm{~h}$ and then quenched in water at room temperature to enhance the hardness. Specimens were then aged at $180{ }^{\circ} \mathrm{C}$ for $5 \mathrm{~h}$ and cooled at room temperature [41]. After the heat treatment and aging cycle, the hardness of the specimens was increased from 120

Fig. 1 Research methodology

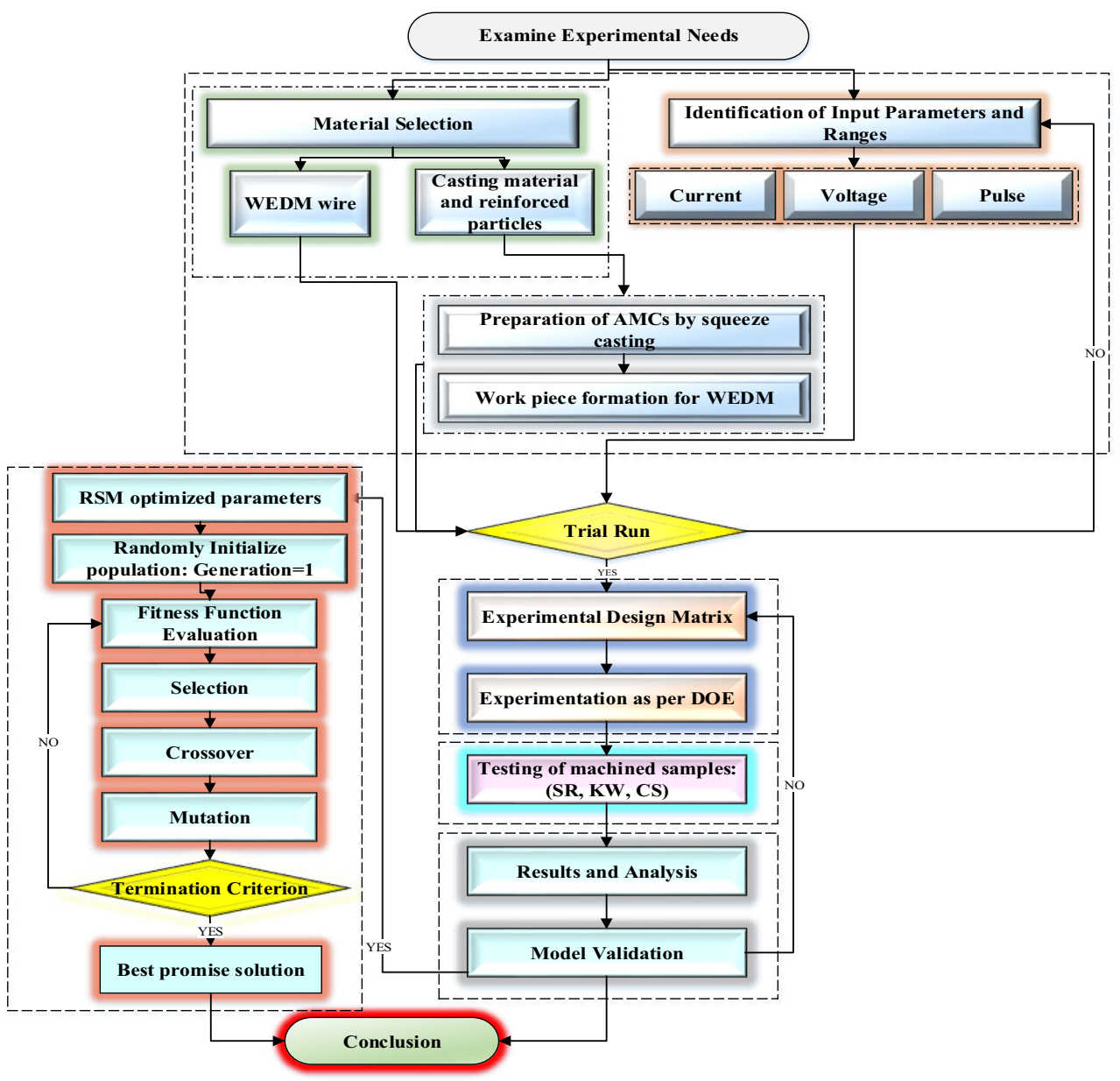


Table 1 Chemical composition of base metal (Al 6061)

\begin{tabular}{lllllllll}
\hline $\mathrm{Mg}$ & $\mathrm{Si}$ & $\mathrm{Cu}$ & $\mathrm{Zn}$ & $\mathrm{Cr}$ & $\mathrm{Fe}$ & $\mathrm{Ti}$ & $\mathrm{Mn}$ & $\mathrm{Al}$ \\
\hline 0.9 & 0.65 & 0.24 & 0.25 & 0.07 & 0.7 & 0.15 & 0.16 & Balanced
\end{tabular}

to $134 \mathrm{HV}$. The hardness of three different specimens was measured by introducing a load of $0.5 \mathrm{~kg}$ for $20 \mathrm{~s}$ on a micro-Vickers hardness tester, and their mean value is regarded as the hardness of prepared AMC. Ultimate tensile strength (UTS) of prepared AMC was tested on a universal testing machine which was observed as $251 \mathrm{MPa}$. SEM micrograph of the squeeze casted AMC showed the uniform distribution of the $\mathrm{SiC}$ particles, as can be seen in Fig. 2e. However, few clusters of particles may exist due to the highpressure compression during solidification. Machining of specimens prepared by the squeeze casting process was carried out on the wire electric discharge machine as shown in Fig. 3. Molybdenum wire of $0.18 \mathrm{~mm}$ diameter was used as an electrode in WEDM of A16061-7.5\% SiC composite. Distilled water was employed as a dielectric medium between the tool and workpiece for the machining of squeeze casted AMC.

Preliminary experimentation was performed to find the ranges of the control parameters. Though the selection of the input variables was done on their well-proven effect on the set responses as evidenced in the reported literature, for specifying their ranges, preliminary trials were performed as no significant literature is available. Therefore, ranges were specified on the basis of preliminary trials. During the initial trials, wire breakage was the defined rationale for the selection of parametric levels. These parametric levels were used for mature experimentation that warranted the minimum chances of wire breakage. The parameters other than control variables were kept constant which is the limitation of this study. Moreover, the results of experimentation are only applicable within the defined range of parameters based on preliminary trials. A cavity of $5 \mathrm{~mm} \times 4 \mathrm{~mm}$ was machined during each experimental trial. The description of the machined cavity, machined specimen, and kerf width in terms of $3 \mathrm{D}$ schematic and actual machined is provided in Fig. 3. Based on the number of control variables and their respective levels, response surface methodology (RSM) was used for experimental design. In RSM, second-order polynomial function best describes the system behavior [42]. For empirical modeling, response measures $Y$ are expressed in Eq. 1.

$Y=f(I, V, P)$

where $f$ represents response surface function; current (I), voltage $(V)$, and pulse $(P)$ are the input parameters. In this study, Box-Behnken RSM design was used for the design of experiments using three process parameters. From the detailed literature review, three process parameters, including current, voltage and pulse, were observed as potent parameters and selected as input parameters in the present research. For three input parameters, the Box-Behnken RSM design yields 15 number of experiments. The experimental design matrix with measured response values is
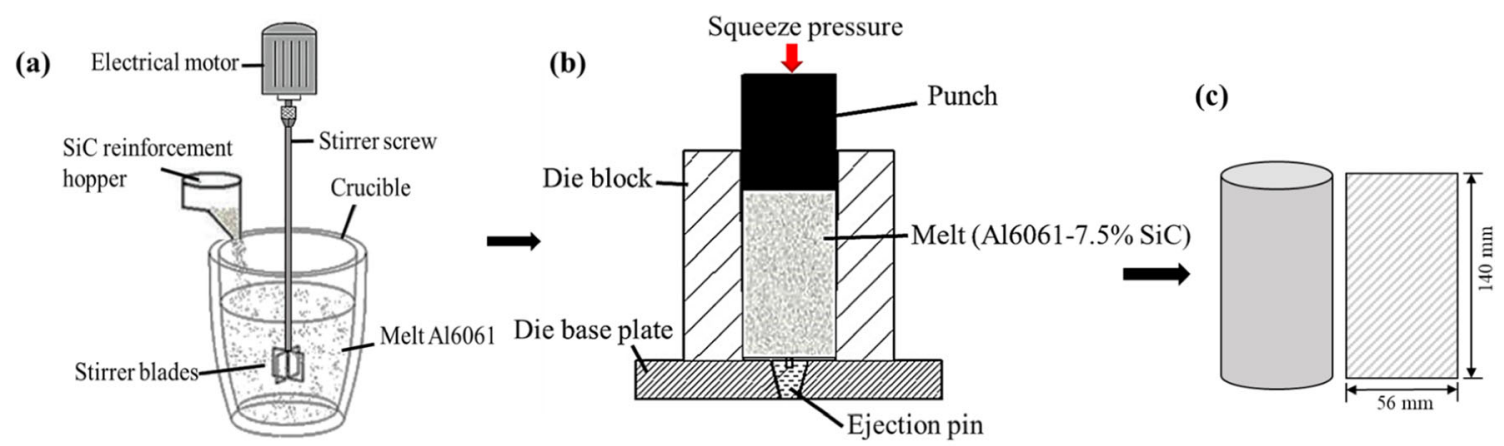

(d)

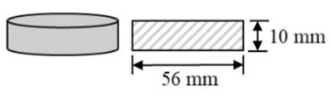

(e)

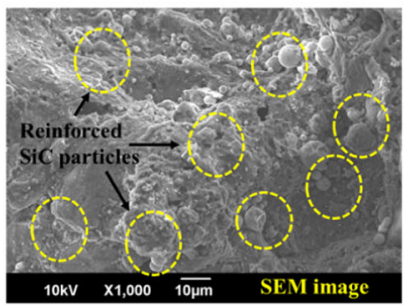

Fig. 2 Schematic illustration. a Mechanical stirring of SiC reinforcement in melt Al6061. b Squeeze casting process. c Casted billet of Al6061-7.5\% SiC composite. d Workpiece. e SEM image 
Fig. 3 Workpiece illustration. a Schematic of the workpiece, machine cavity and cut specimen. b Actual workpiece, machined cavity and cut specimen

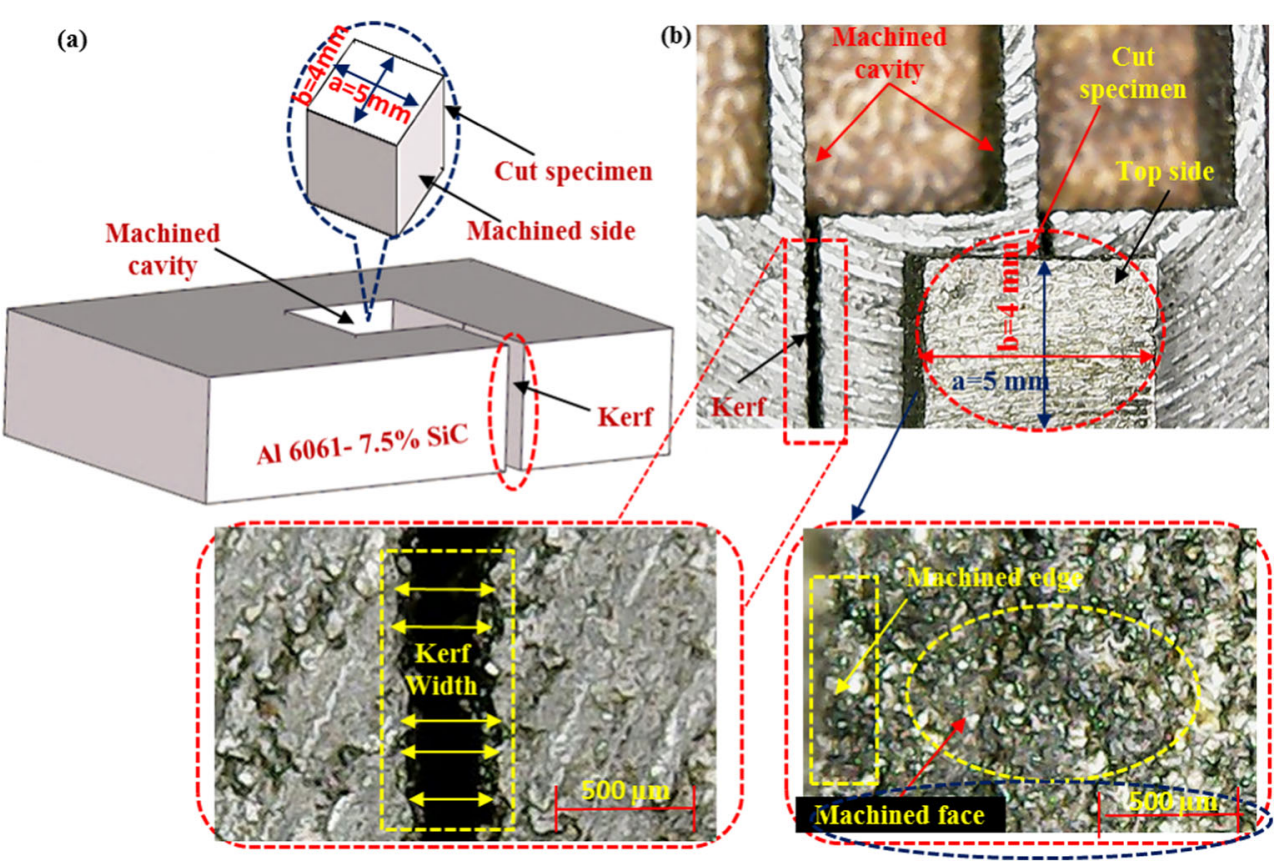

given in Table 2. Machining of squeeze casted AMCs was analyzed based on $S_{\mathrm{R}}, K_{\mathrm{W}}$ and $C_{\mathrm{S}}$. Response values of $C_{\mathrm{S}}$ were recorded from the control unit of the wire electric discharge machine for all the experiments. These values were also verified by recording machining time for each experiment individually. Surface roughness testing machine (SJ-410) was used to calculate the surface roughness of each of the machined sample. An evaluation length of $4 \mathrm{~mm}$ and cut-off length of $0.8 \mathrm{~mm}$ were set for the measurement of surface roughness in terms of arithmetic average. Five readings were recorded for each sample, and then, their standard deviation was calculated. Considering that the magnitude of standard deviation in all of the experimental trials was quite low, the average value of surface roughness has been reported herein. For the measurement of kerf width, coordinate measuring machine (CMM: CE-450DV), having a resolution of $0.001 \mathrm{~mm}$ was employed. The width of the kerf was measured at five different points along the kerf, and then, the average value is reported herein. The procedure opted for
Table 2 Experimental design with measured response values

\begin{tabular}{|c|c|c|c|c|c|c|}
\hline \multirow[t]{2}{*}{ Sr. No. } & \multicolumn{3}{|c|}{ Input parameters } & \multicolumn{3}{|c|}{ Responses } \\
\hline & Current A & Voltage V & Pulse mu & $S_{\mathrm{R}} \mu \mathrm{m}$ & $K_{\mathrm{W}} \mathrm{mm}$ & $C_{\mathrm{S}} \mathrm{mm} / \mathrm{min}$ \\
\hline 1 & 3 & 75 & 15 & 8.10 & 0.321 & 4.02 \\
\hline 2 & 5 & 75 & 15 & 8.73 & 0.377 & 4.02 \\
\hline 3 & 3 & 85 & 15 & 8.54 & 0.325 & 3.36 \\
\hline 4 & 5 & 85 & 15 & 12.14 & 0.389 & 5.94 \\
\hline 5 & 3 & 80 & 10 & 6.54 & 0.318 & 5.76 \\
\hline 6 & 5 & 80 & 10 & 7.69 & 0.372 & 3.06 \\
\hline 7 & 3 & 80 & 20 & 6.28 & 0.316 & 3.24 \\
\hline 8 & 5 & 80 & 20 & 8.83 & 0.401 & 3.60 \\
\hline 9 & 4 & 75 & 10 & 7.22 & 0.331 & 3.90 \\
\hline 10 & 4 & 85 & 10 & 6.63 & 0.327 & 4.20 \\
\hline 11 & 4 & 75 & 20 & 5.20 & 0.345 & 3.18 \\
\hline 12 & 4 & 85 & 20 & 10.67 & 0.357 & 4.14 \\
\hline 13 & 4 & 80 & 15 & 7.88 & 0.350 & 6.00 \\
\hline 14 & 4 & 80 & 15 & 8.48 & 0.346 & 6.18 \\
\hline 15 & 4 & 80 & 15 & 7.96 & 0.348 & 4.32 \\
\hline
\end{tabular}


kerf measurement has also been demonstrated in Fig. 4 for better understanding.

\section{Results and discussion}

\subsection{Parametric significance analysis}

The values of the defined response characteristics were found upon the successful conclusion of the experimentation under RSM based experimental design. The results of experimentation along with the experimental design table are mentioned in Table 2. Afterwards, various statistical and microscopic analyses were carried out to envisage the effect of control variables on the set responses. First of all, analysis of variance (ANOVA) was performed to examine the parametric significance with respect to the responses [43]. ANOVA was performed at a confidence interval of $95 \%$, which means any control variable or term whose probability value is lesser than 0.05 was considered significant for the defined response. Terms with probability values greater than 0.05 were considered insignificant, which means such terms have very minor contribution in affecting the set response measure. ANOVA results have been tabulated in Table 3. Results reveal that not only the main effects' terms are noticed significant rather, some interaction, and quadratic terms are also proved significant as depicted in Table 3. For instance, in case of surface roughness, main effects of current (A), voltage (B), and pulse $(C)$, interaction effects of current and voltage $(A B)$, voltage and pulse $(\mathrm{BC})$ and quadratic effects of current $\left(\mathrm{A}^{2}\right)$, voltage $\left(B^{2}\right)$ and pulse $\left(C^{2}\right)$ are observed significant for $S_{R}$. Similarly, in case of kerf width, current $(\mathrm{A})$, pulse $(\mathrm{C})$, current $\times$ pulse (AC) and current $\left(\mathrm{A}^{2}\right)$ are the significant model terms. However, for the cutting speed, the main and quadratic factors that have significant contributions are current (A), pulse (C) and pulse ${ }^{2}\left(C^{2}\right)$.

\subsection{Parametric effects analysis}

\subsubsection{Surface roughness}

After finding the parametric significance, 3D surface plot analysis was performed. 3D response surface graphs were employed to evaluate and visualize the collective influence of two parameters at the same time [42]. Figure 5 a demonstrates the effect of voltage and current on surface roughness. It has been observed that surface roughness has increasing relation with both parameters. The said parameters have a pivot role in deciding the amount of discharge energy in the workpiec-electrode gap. At high value of voltage and current, greater electrical power is available that led to the formation of powerful plasma channel. Intense sparking is realized in the cutting regime because of the higher magnitude of the discharge energy [44]. This energy introduces a localized heat flux into the target surface that causes strong melting and vaporization of the work surface. Thus, deep craters are formed at the machined surface, which give rise to the roughness of the machined surface $[25,26]$. This has also been

Fig. 4 Kerf measurement

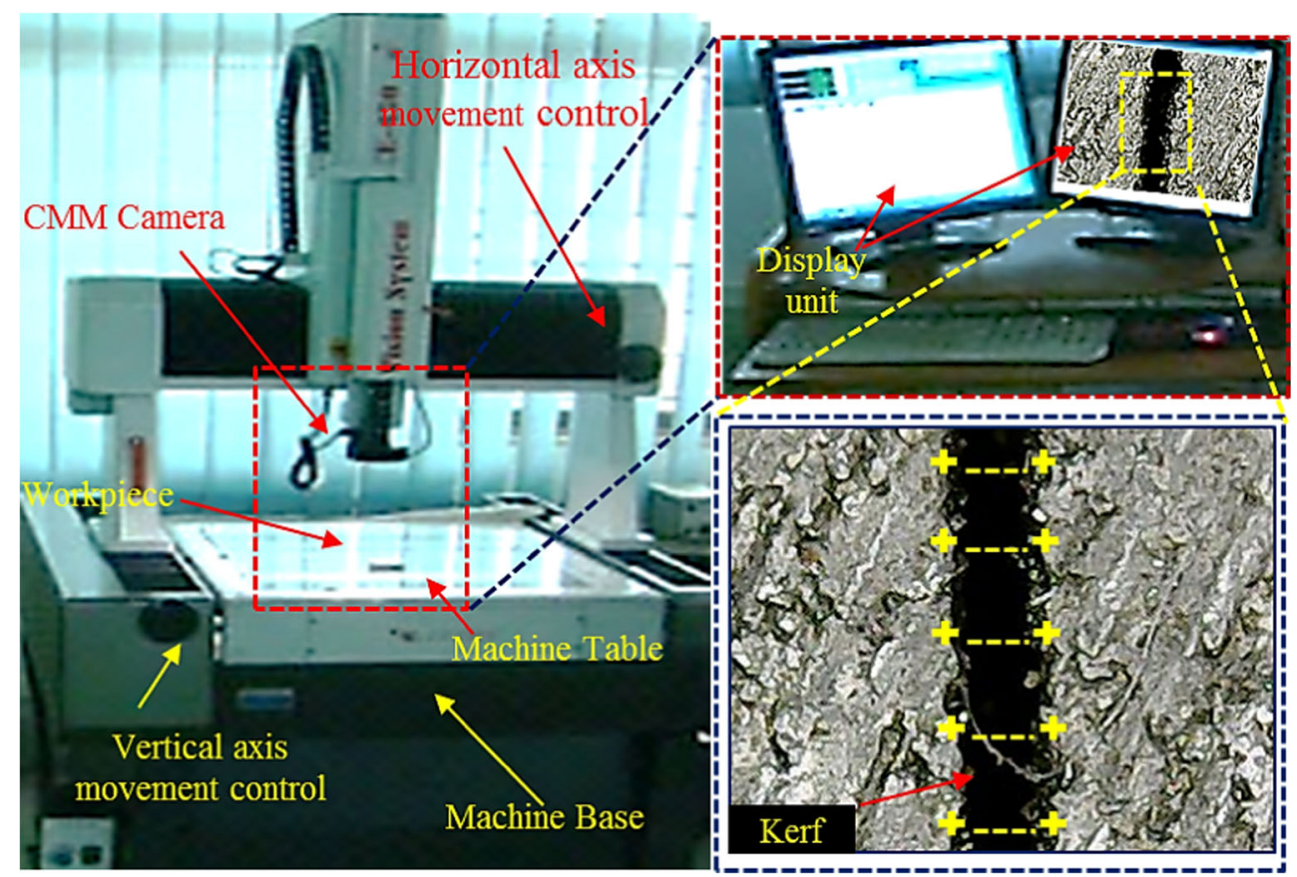


Table 3 Analysis of variance for observed responses $\left(\mathrm{S}_{\mathrm{R}}, \mathrm{K}_{\mathrm{W}}\right.$ and $\left.\mathrm{C}_{\mathrm{S}}\right)$

Surface roughness

\begin{tabular}{|c|c|c|c|c|c|c|}
\hline Source & SS & $d f$ & MS & $F$ value & $p$ value & \\
\hline Model & 40.24 & 9 & 4.47 & 30.73 & 0.0007 & Significant \\
\hline A-current & 7.80 & 1 & 7.80 & 53.62 & 0.0007 & \\
\hline $\mathrm{B}$-voltage & 9.90 & 1 & 9.90 & 68.05 & 0.0004 & \\
\hline $\mathrm{C}$-pulse & 1.28 & 1 & 1.28 & 8.80 & 0.0313 & \\
\hline $\mathrm{AB}$ & 1.96 & 1 & 1.96 & 13.47 & 0.0144 & \\
\hline $\mathrm{AC}$ & 0.42 & 1 & 0.42 & 2.90 & 0.1491 & \\
\hline $\mathrm{BC}$ & 8.70 & 1 & 8.70 & 59.81 & 0.0006 & \\
\hline $\mathrm{A}^{2}$ & 1.22 & 1 & 1.22 & 8.39 & 0.0339 & \\
\hline $\mathrm{B}^{2}$ & 1.44 & 1 & 1.44 & 9.91 & 0.0254 & \\
\hline $\mathrm{C}^{2}$ & 6.73 & 1 & 6.73 & 46.25 & 0.0010 & \\
\hline Residual & 0.73 & 5 & 0.15 & & & \\
\hline Lack of fit & 0.49 & 3 & 0.16 & 1.35 & 0.4515 & Not significant \\
\hline Pure error & 0.24 & 2 & 0.12 & & & \\
\hline Cor total & 40.96 & 14 & & & & \\
\hline Std. Dev. & 0.38 & & $\mathrm{R}^{2}$ & & 0.9822 & \\
\hline Mean & 8.02 & & Adjusted $R^{2}$ & & 0.9503 & \\
\hline C.V. $\%$ & 4.76 & & Predicted $R^{2}$ & & 0.7964 & \\
\hline Press & 8.34 & & Adeq precision & & 22.195 & \\
\hline \multicolumn{7}{|l|}{ Kerf width } \\
\hline Model & $9.82 \times 10^{-3}$ & 9 & $1.09 \times 10^{-3}$ & 56.09 & 0.0002 & Significant \\
\hline $\mathrm{A}$-current & $8.38 \times 10^{-3}$ & 1 & $8.38 \times 10^{-3}$ & 431.11 & $<0.0001$ & \\
\hline $\mathrm{B}$ - voltage & $7.20 \times 10^{-5}$ & 1 & $7.20 \times 10^{-5}$ & 3.70 & 0.1124 & \\
\hline $\mathrm{C}-$ pulse & $6.30 \times 10^{-4}$ & 1 & $6.30 \times 10^{-4}$ & 32.40 & 0.0023 & \\
\hline $\mathrm{AB}$ & $1.60 \times 10^{-5}$ & 1 & $1.60 \times 10^{-5}$ & 0.82 & 0.4060 & \\
\hline $\mathrm{AC}$ & $2.40 \times 10^{-4}$ & 1 & $2.40 \times 10^{-4}$ & 12.35 & 0.0170 & \\
\hline $\mathrm{BC}$ & $6.40 \times 10^{-5}$ & 1 & $6.40 \times 10^{-5}$ & 3.29 & 0.1294 & \\
\hline $\mathrm{A}^{2}$ & $2.59 \times 10^{-4}$ & 1 & $2.59 \times 10^{-4}$ & 13.32 & 0.0148 & \\
\hline $\mathrm{B}^{2}$ & $4.20 \times 10^{-5}$ & 1 & $4.20 \times 10^{-5}$ & 2.16 & 0.2014 & \\
\hline$C^{2}$ & $7.89 \times 10^{-5}$ & 1 & $7.89 \times 10^{-5}$ & 4.06 & 0.1000 & \\
\hline Residual & $9.72 \times 10^{-5}$ & 5 & $1.94 \times 10^{-5}$ & & & \\
\hline Lack of fit & $8.92 \times 10^{-5}$ & 3 & $2.97 \times 10^{-5}$ & 7.44 & 0.1208 & Not significant \\
\hline Pure error & $8.00 \times 10^{-6}$ & 2 & $4.00 \times 10^{-6}$ & & & \\
\hline Cor total & $9.92 \times 10^{-3}$ & 14 & & & & \\
\hline Std. Dev. & $4.41 \times 10^{-3}$ & & $R^{2}$ & & 0.9902 & \\
\hline Mean & 0.35 & & Adjusted $R^{2}$ & & 0.9725 & \\
\hline C.V. $\%$ & 1.27 & & Predicted $R^{2}$ & & 0.8542 & \\
\hline Press & $1.45 \times 10^{-3}$ & & Adeq precision & & 22.911 & \\
\hline \multicolumn{7}{|c|}{ Cutting speed } \\
\hline Model & 16.72 & 9 & 1.86 & 59.78 & 0.0001 & Significant \\
\hline A-current & 0.22 & 1 & 0.22 & 7.01 & 0.0456 & \\
\hline B-voltage & 0.029 & 1 & 0.029 & 0.93 & 0.3799 & \\
\hline $\mathrm{C}$-pulse & 15.24 & 1 & 15.24 & 490.19 & $<0.0001$ & \\
\hline $\mathrm{AB}$ & 0.014 & 1 & 0.014 & 0.46 & 0.5263 & \\
\hline $\mathrm{AC}$ & $3.60 \times 10^{-3}$ & 1 & $3.60 \times 10^{-3}$ & 0.12 & 0.7474 & \\
\hline $\mathrm{BC}$ & 0.014 & 1 & 0.014 & 0.46 & 0.5263 & \\
\hline $\mathrm{A}^{2}$ & $9.23 \times 10^{-3}$ & 1 & $9.23 \times 10^{-3}$ & 0.30 & 0.6092 & \\
\hline $\mathrm{B}^{2}$ & 0.018 & 1 & 0.018 & 0.58 & 0.4799 & \\
\hline
\end{tabular}


Table 3 (continued)

Surface roughness

\begin{tabular}{|c|c|c|c|c|c|c|}
\hline Source & SS & $d f$ & MS & $F$ value & $p$ value & \\
\hline$C^{2}$ & 1.16 & 1 & 1.16 & 37.26 & 0.0017 & \\
\hline Residual & 0.16 & 5 & 0.031 & & & \\
\hline Lack of fit & 0.11 & 3 & 0.037 & 1.61 & 0.4061 & Not significant \\
\hline Pure error & 0.046 & 2 & 0.023 & & & \\
\hline Cor total & 16.88 & 14 & & & & \\
\hline Std. Dev. & 0.18 & & $R^{2}$ & & 0.9908 & \\
\hline Mean & 4.33 & & Adjusted $R^{2}$ & & 0.9742 & \\
\hline C.V. $\%$ & 4.07 & & Predicted $R^{2}$ & & 0.8898 & \\
\hline Press & 1.86 & & Adeq precision & & 21.779 & \\
\hline
\end{tabular}

witnessed in the optical and SEM micrographs presented in Figs. 6 and 7, respectively. The machined surface is subjected to deep craters at higher values of both current and voltages, as evidenced in optical micrograph shown in Fig. 6b. The same has also been witnessed in the SEM micrographs of the machined surface presented in Fig. 7b. The machined surface clearly depicts the presence of deep craters. The greater size of micro globules and re-deposited melted debris is also evident. These cutting imperfactions ultimately translated into a poor surface finish. Contrary to that, the surface of a machined specimen whose cutting is done on lower values of both the said control variables is noticeably better in terms of surface irregularities, as highlighted in Figs. 6 and 7. The machined surface is subjected to shallow craters, as demonstrated in the optical micrographs shown in Fig. 6 a, c and d. This argument has also been validated by the SEM micrographs provided in Fig. 7a, c and d. The cut surfaces contain shallow craters along with the smaller size of re-deposited melted debris and micro globules. It has also been observed from the optical and SEMbased evidences of the machined surfaces that the influence of voltage in determining the magnitude of $S_{\mathrm{R}}$ is more influential in contrast to that of current. The superior influence of voltage in contrast to the current has also been verified from $3 \mathrm{D}$ surface plots described in Fig. 3 and ANOVA results mentioned in Table 3. The combined effect of pulse and current on surface roughness is illustrated in Fig. 5b. It has been noticed that $S_{\mathrm{R}}$ has non-linear increasing relation with the pulse and increasing relation with the current. Surface roughness is maximum at middle level of pulse and higher level of current. Because high current resulting in vigorous explosions in cutting zone resulting in deeper craters on the machined surface, which yields high surface roughness [21, 45]. The inferior quality of cut surface at the middle level of pulse and high level of current has also noted in the optical and SEM micrographs provided in Figs. $6 \mathrm{~b}$ and $7 \mathrm{~b}$, respectively. The minimum value of $S_{\mathrm{R}}$ has been found at low levels of pulse and current. If the effect of the pulse is coupled with the voltage, it has been revealed that voltage has a more significant effect on surface roughness than pulse, as demonstrated in Fig. 5c. Better surface quality is observed at low values of voltage and higher values of the pulse. The pulse is primarily involved in determining the spark gap and its lower value means that wire electrode will stay a bit away from the target surface. Therefore, the amount of discharge energy transferred to the workpiece is compromised and its substantial part got consumed by the dielectric fluid. Since voltage holds a primary
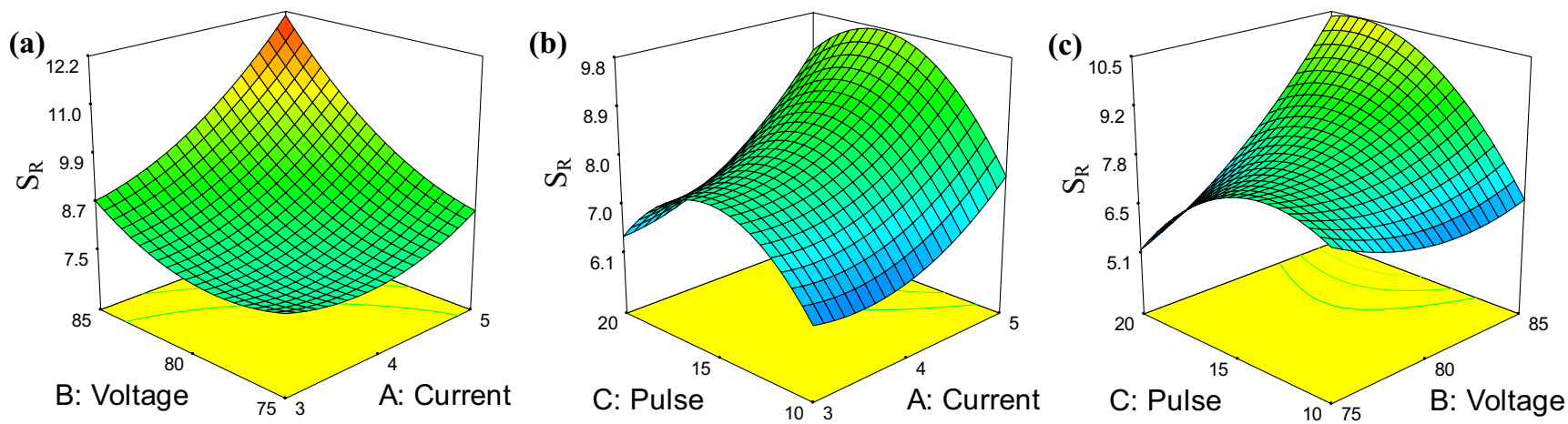

Fig. 5 3D surface plots showing the effects of a voltage and current, $\mathbf{b}$ pulse and current, $\mathbf{c}$ pulse and voltage on $S_{\mathrm{R}}$ 
Fig. 6 Micrographs of machined surface a current $3 \mathrm{~A}$, voltage 80 $\mathrm{V}$, pulse $20 \mathrm{mu}$; b current $5 \mathrm{~A}$, voltage $85 \mathrm{~V}$, pulse $15 \mathrm{mu}$; current $4 \mathrm{~A}$, voltage $80 \mathrm{~V}$, pulse $20 \mathrm{mu}$; d current $4 \mathrm{~A}$, voltage 75 $\mathrm{V}$, pulse $20 \mathrm{mu}$
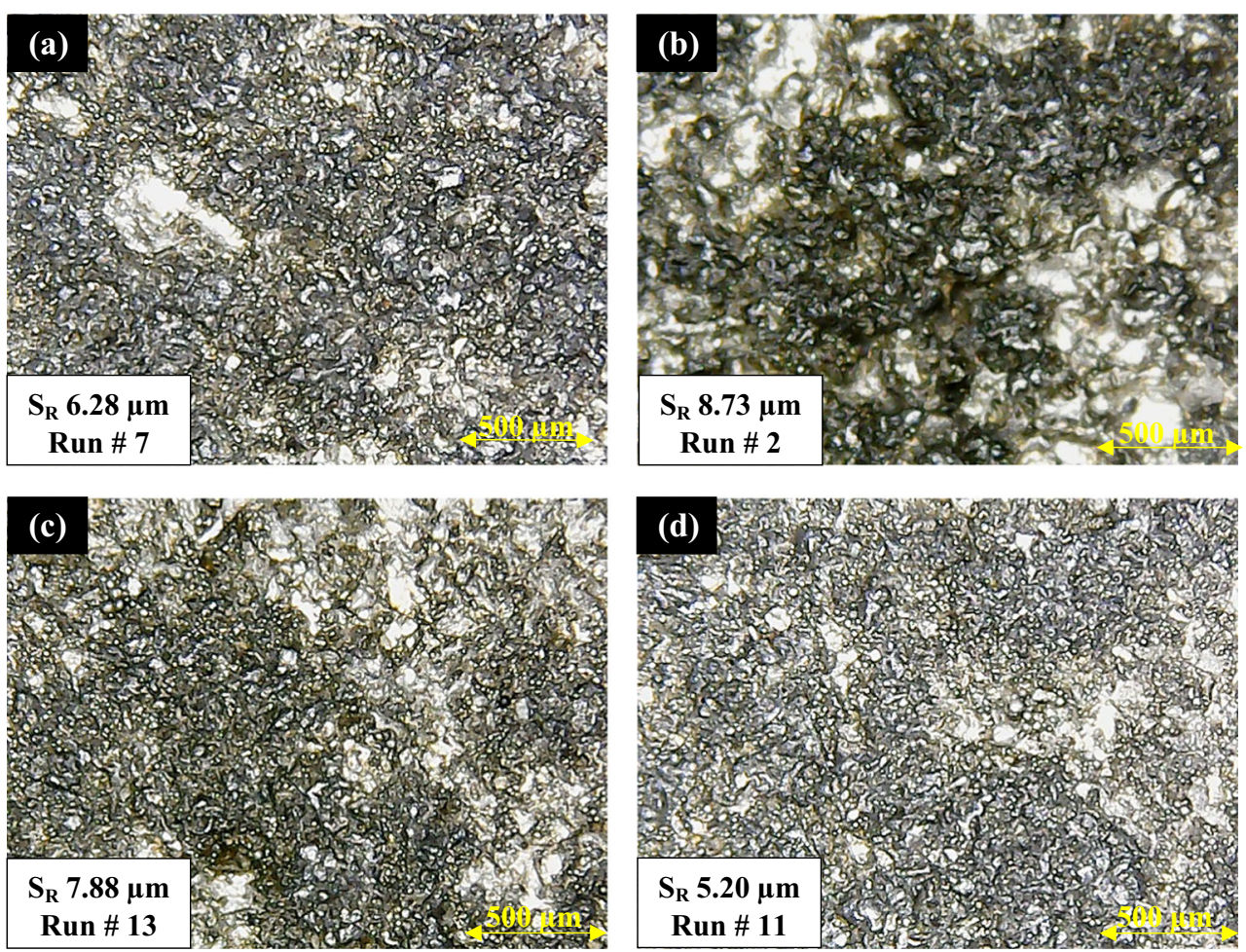

importance in deciding the amount of discharge energy and its lower value means low magnitude of discharge energy, thus, when high value of pulse is coupled with low voltages, shallow craters are seemed on the machined area due to reduced discharge energy involvement during cutting as demostrated in Figs. 6d and 7d. Contrarily, poor surface
Fig. 7 SEM images of machined surface a current $3 \mathrm{~A}$, voltage 80 $\mathrm{V}$, pulse $20 \mathrm{mu}$; b current $5 \mathrm{~A}$, voltage $85 \mathrm{~V}$, pulse $15 \mathrm{mu}$; c current $4 \mathrm{~A}$, voltage $80 \mathrm{~V}$, pulse $20 \mathrm{mu}$; d current $4 \mathrm{~A}$, voltage 75 $\mathrm{V}$, pulse $20 \mathrm{mu}$

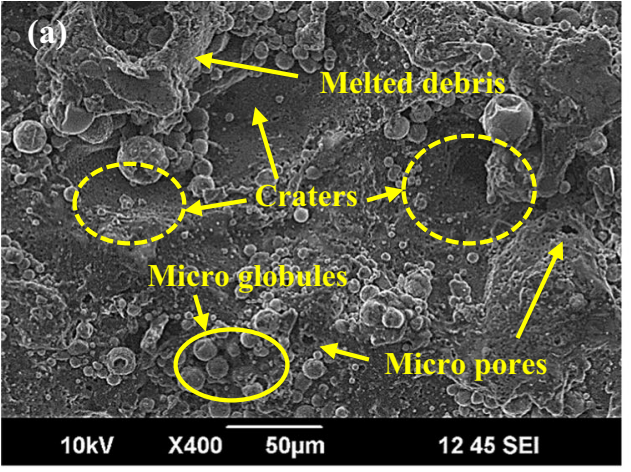

Run \# $7\left(\mathrm{~S}_{\mathrm{R}} 6.28, \mathrm{~K}_{\mathrm{W}} 0.316, \mathrm{C}_{\mathrm{S}} 3.24\right)$

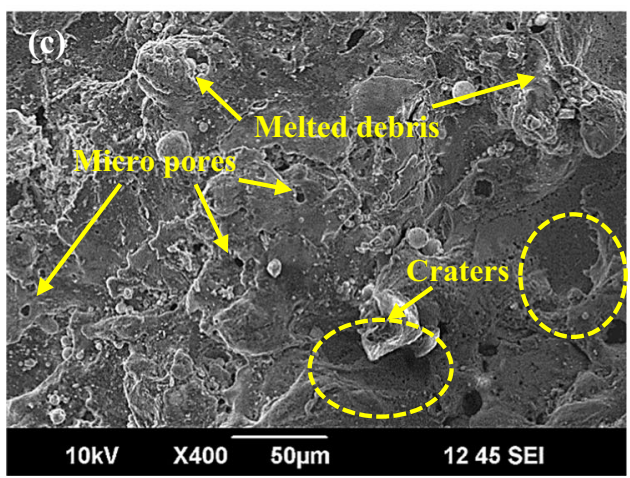

Run \# $13\left(\mathrm{~S}_{\mathrm{R}} 7.88, \mathrm{~K}_{\mathrm{W}} 0.350, \mathrm{C}_{\mathrm{S}} 6.0\right)$

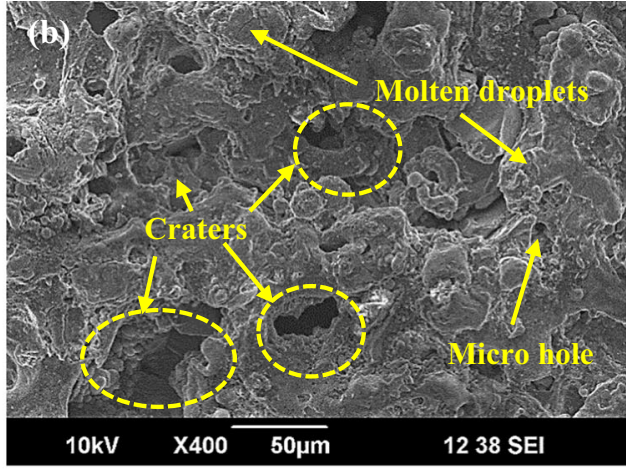

Run \# $2\left(\mathrm{~S}_{\mathrm{R}} 8.73, \mathrm{~K}_{\mathrm{W}} 0.377, \mathrm{C}_{\mathrm{S}} 4.02\right)$

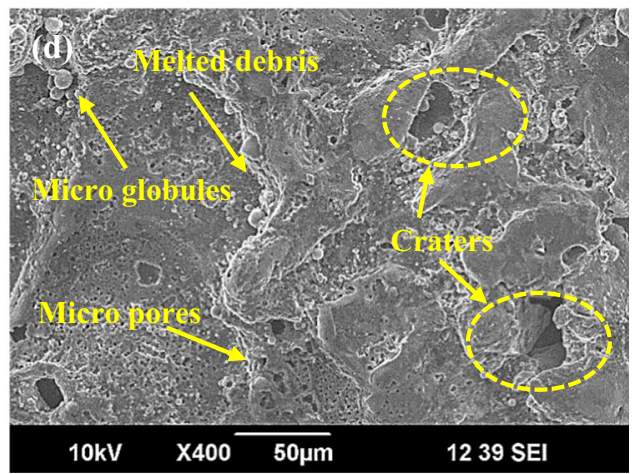

Run \# $11\left(\mathrm{~S}_{\mathrm{R}} 5.20, \mathrm{~K}_{\mathrm{W}} 0.345, \mathrm{C}_{\mathrm{S}} 3.18\right)$ 


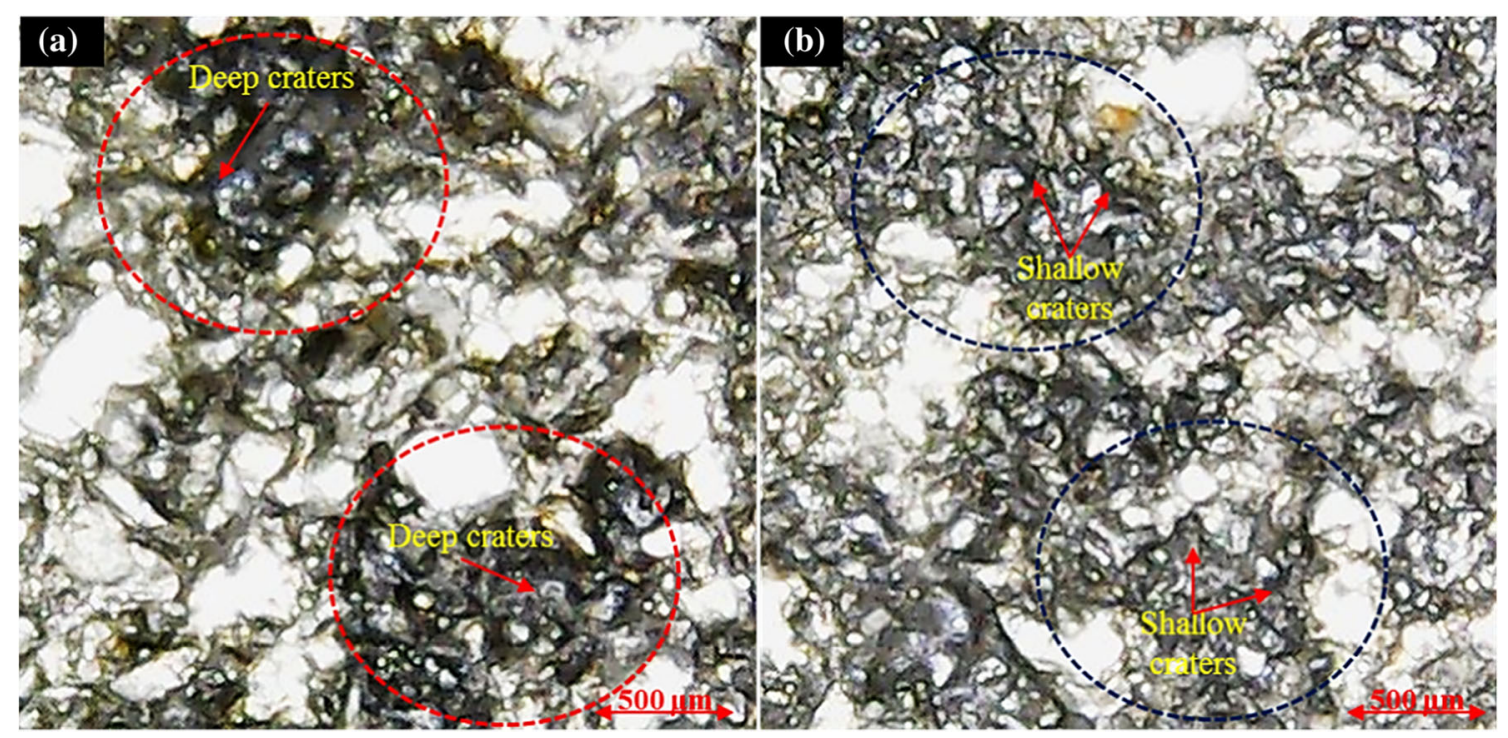

Fig. 8 Optical micrographs of machined surface at a pulse $10 \mathrm{mu}$, voltage $85 \mathrm{~V}$ and b pulse $20 \mathrm{mu}$, voltage $75 \mathrm{~V}$

quality is obtained at high level of voltage and low level of pulse, because low pulse value provides small spark gap which helps the high voltage to create stronger electric field. Subsequently, erosion of the workpiece material takes place quickly due to instant sparking that finally yields coarse surface [23]. The same has also been indicated in the optical micrographs shown in Fig. 8.

\subsubsection{Kerf width}

The effect of voltage and current on the kerf width are graphically represented in Fig. 9a. This graph describes that kerf width is maximum at higher values of current and voltage. It has a linearly increasing relation with the current. As the current is increased, the kerf width is also increased. Moreover, the effect of the current is more prominent on kerf width as compared with the voltage, as depicted in Fig. 9a. With the increase in both current and voltage, more powerful explosions take place that are likely to generate more amount of discharge energy in the cutting regime. Consequently, intense localized heat is induced in the target material that erodes a greater amount of material and causes the widening of the cut slot [46]. The widening of the kerf at higher values of current and voltage is also demonstrated in optical micrographs provided in Fig. 10a, b. The effect of current in conjunction with the pulse is described in Fig. 9b. The value of kerf width increases with the rise in the magnitude of current and pulse. A larger amount of current promotes powerful explosions of energy that cause intense sparking. Such sparking creates wider and deeper craters in the target material which resulted in widening of the machined kerf [47]. However, the current has a more pronounced impact on the kerf width in contrast to the pulse, as indicated in Fig. 9b. The combined effect of pulse and voltage on $K_{\mathrm{W}}$ is described in Fig. 9c. It is observed that pulse holds an immensely high influence on $K_{\mathrm{W}}$ in comparison with the voltage. The minimum value of kerf width is achieved at low values of pulse and voltage, as highlighted in Fig. 9c. At a reduced value of pulse, the corresponding
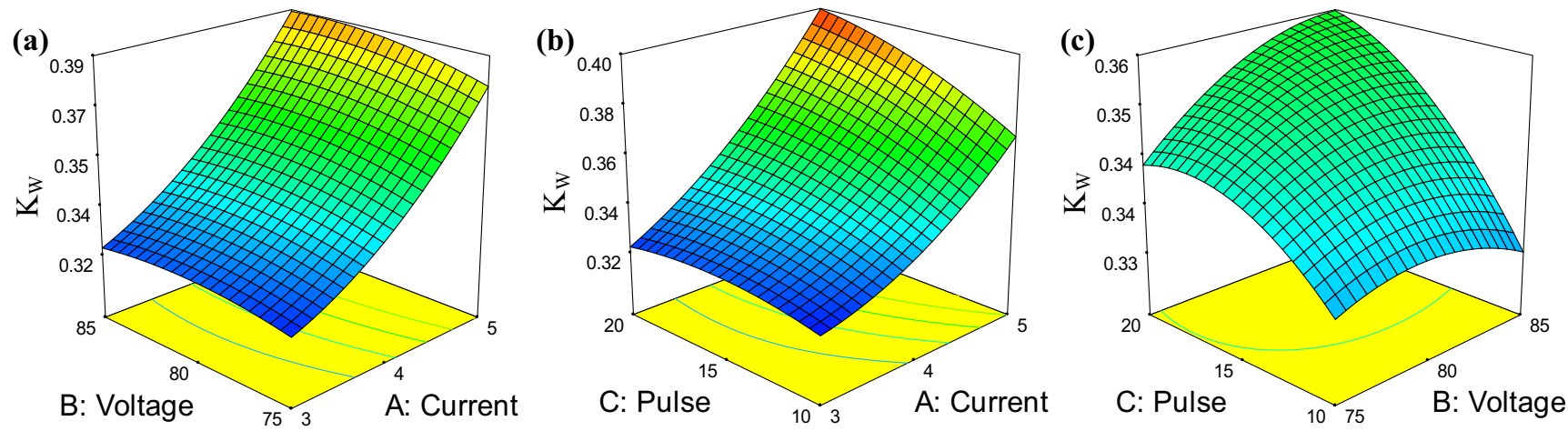

Fig. 9 3D surface plots showing the effects of a voltage and current, b pulse and current, $\mathbf{c}$ pulse and voltage on $K_{\mathrm{W}}$ 


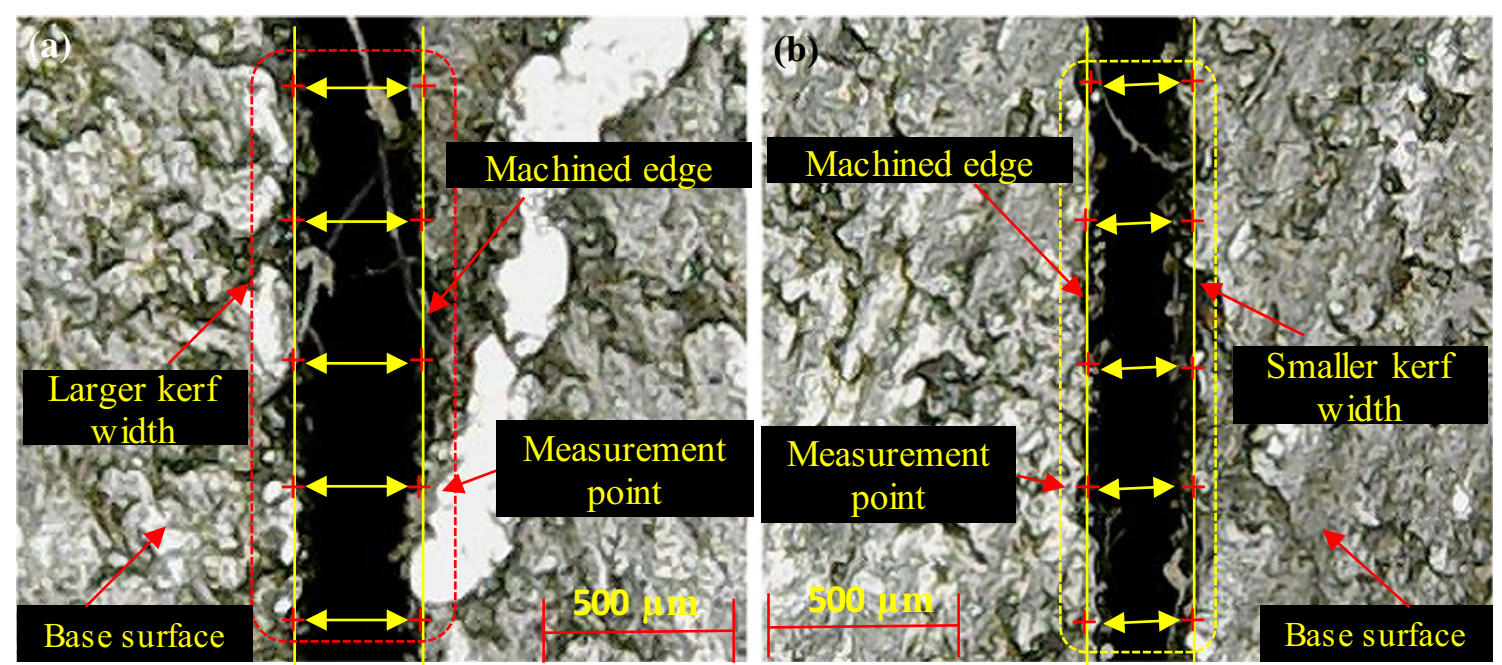

Fig. 10 Kerf width at a current $5 \mathrm{~A}$, voltage $85 \mathrm{~V}$, pulse $15 \mathrm{mu}$ and $\mathbf{b}$ current $3 \mathrm{~A}$, voltage $75 \mathrm{~V}$, pulse $15 \mathrm{mu}$

spark gap is smaller and low magnitude of voltage yields lesser discharge energy. It has already been reported that low discharge energy is required at less spark gap for smooth machining [20]. Therefore, a narrow kerf is achieved.

\subsubsection{Cutting speed}

The effects of control variables with respect to the third response, i.e. cutting speed, are described in Fig. 11. It has been revealed from the 3D plot shown in Fig. 11a that both current and voltages are significantly influencing the cutting rate during WEDM of Al6061-7.5\% SiC composite. A prominent rise in cutting speed has been reported at a high level of the two control parameters namely current and voltage. However, the current holds a more influential role in governing the magnitude of cutting speed as compared with the voltage. Basically, at high value of discharge current, pulse energy increases, and when this effect is combined with high voltage, an intense sparking occurs that readily melts and evaporates the workpiece material. Therefore, cutting rate upsurges noticeably [48]. If the effect of current is observed in combination with the pulse, an inverse relation of pulse with cutting speed is noticed as demonstrated in the surface plot shown in Fig. $11 \mathrm{~b}$, i.e. low pulse yields better cutting speed, whereas the impact of current remains the same for cutting speed as was in conjunction with voltage, i.e. rise in the current magnitude provides a high cutting rate. Maximum cutting speed is obtained at a low value of pulse and higher value of current. Low pulse value kept the wire electrode near the target material, thus ensuring the effective transfer of discharge energy into the workpiece, whereas high current yields high discharge energy that causes a swift melting and vaporization of work material. The availability of larger discharge energy in conjunction with its effective transfer to work surface results in enhanced cutting rate [49]. The value of the cutting rate also seemed sensitive to the change in the values of both voltage and pulse as illustrated in Fig. 11c. The trends of both control parameters with respect to the cutting rate are opposite to each other. Pulse depicts an inverse relationship with cutting speed, whereas voltage represents a direct relation, i.e. the cutting rate is improved at low pulse and high voltage, as witnessed in Fig. 11c. In WEDM process, voltage is responsible for
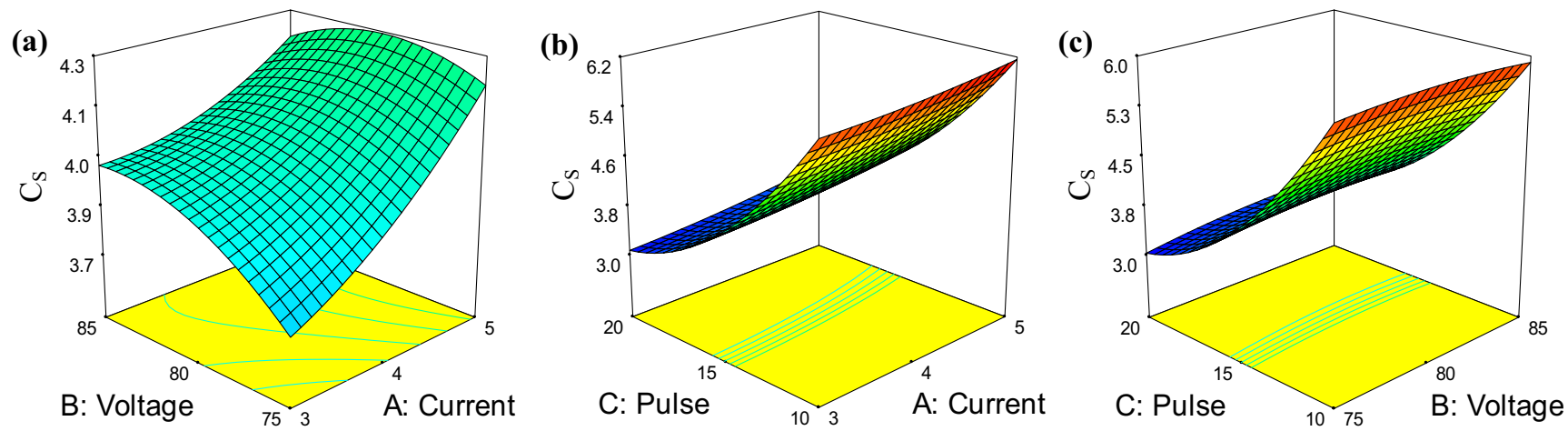

Fig. $113 \mathrm{D}$ plots showing the effects of a voltage and current, $\mathbf{b}$ pulse and current, $\mathbf{c}$ pulse and voltage on $C_{\mathrm{S}}$ 
initiating the electrical sparking by ionizing the dielectric fluid. An increase in the voltage strengthens the electric field in the machining zone because the delay time of discharge is decreased. High voltage produces spark discharge easily and effectively, which removes work material swiftly, giving high cutting speed [50].

\subsection{Empirical modeling}

Empirical models of responses $\left(S_{\mathrm{R}}, K_{\mathrm{W}}\right.$ and $\left.\mathrm{C}_{\mathrm{S}}\right)$ have also been proposed after comprehensively discussing the parametric effects for the defined output variables using regression analysis. The significance of the developed models has been tested through analysis of variance (ANOVA), which is a commonly used statistical tool [51]\{Raza, $2019 \# 1147\}$. Adequacy measures are used to evaluate the competence of the models. ANOVA reveals that the formulated models of response measures are significant, as demonstrated by the ANOVA results tabulated in Table 3. Adequacy measures $\left(R^{2}\right.$, adjusted $R^{2}$ and predicted $\left.R^{2}\right)$ found in Table 3 are showing that their values are closer to 1 for all the set responses. This in turn justifies the acceptability and precision of the proposed relations. The developed empirical models for all three conflicting response characteristics, namely surface roughness, kerf width and cutting speed, are described in Eqs. 2, 3 and 4, respectively. The exactness of these models has also been examined by drawing plots between actual versus predicted values. These plots are shown in Fig. 12a-c. It is evident from Fig. 12 that the actual values of all the responses lie closer to the predicted trend line, which affirms the appropriateness of the formulated models.

$$
\begin{aligned}
& R a=+261.7-(15.79 \times \text { Current })-(5.223 \times \text { Voltage })-(3.28 \times \text { Pulse })+(0.14 \times \text { Current } \times \text { Voltage })+(0.065 \times \text { Current } \times \text { Pulse }) \\
& +(0.059 \times \text { Voltage } \times \text { Pulse })+\left(0.575 \times \text { Current }^{2}\right)+\left(0.025 \times \text { Voltage }^{2}\right)-\left(0.054 \times \text { Pulse }^{2}\right) \\
& K f=-0.21475-(0.089875 \times \text { Current })+(0.0182 \times \text { Voltage })-(0.011675 \times \text { Pulse })+(0.0004 \times \text { Current } \times \text { Voltage }) \\
& +(0.00155 \times \text { Current } \times \text { Pulse })+(0.00016 \times \text { Voltage } \times \text { Pulse })+\left(0.00837 \times \text { Current }^{2}\right)-\left(0.000135 \times \text { Voltage }^{2}\right)-\left(0.000185 \times \text { Pulse }^{2}\right)
\end{aligned}
$$

$$
\begin{aligned}
C S= & -6.12+(0.635 \times \text { Current })+(0.472 \times \text { Voltage })-(1.164 \times \text { Pulse })-\left(0.012 \times \text { Current }^{2} \text { Voltage }\right) \\
& +\left(6 \times 10^{-3} \times \text { Current } \times \text { Pulse }\right)+\left(2.4 \times 10^{-3} \times \text { Voltage } \times \text { Pulse }\right)+\left(0.05 \times \text { Current }^{2}\right)-\left(2.8 \times 10^{-3} \times \text { Voltage }^{2}\right)+\left(0.0224 \times \text { Pulse }^{2}\right)
\end{aligned}
$$

Four confirmatory trials were also performed to critically examine the accuracy of the proposed mathematical relations of the output variables. These experiments were performed by arbitrarily selecting the WEDM parametric values. For each of the confirmatory trials, the values of surface roughness, kerf width and cutting speed were measured. The results of the confirmatory trials are provided in Table 4 . For each of the confirmatory tests, both experimental and empirical models' predicted values were compared as illustrated in Fig. 13. Afterwards, a percentage error was calculated using the relationship described in Eq. 5 [52]. It is noteworthy that the formulated empirical relationships can
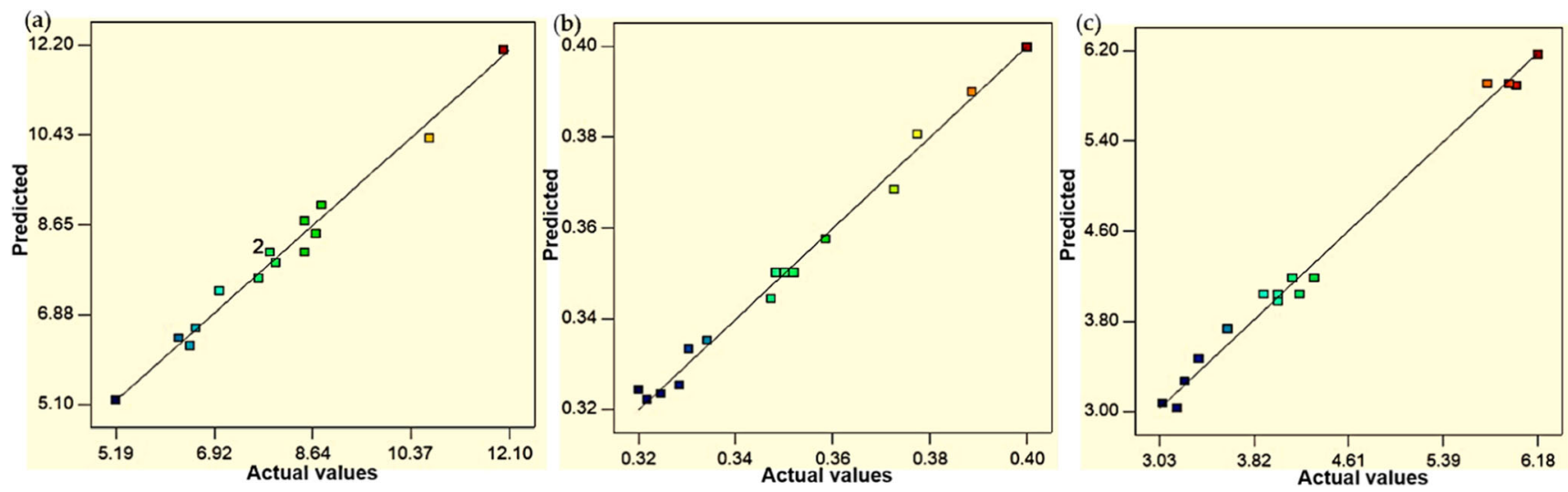

Fig. 12 Predicted model plots against actual response values for a $S_{\mathrm{R}}$, b $K_{\mathrm{W}}$ and $\mathbf{c} C_{\mathrm{S}}$ 
Table 4 Confirmatory trials for $\mathrm{S}_{\mathrm{R}}, \mathrm{K}_{\mathrm{W}}$ and $\mathrm{C}_{\mathrm{S}}$ with predicted and actual values

\begin{tabular}{|c|c|c|c|c|c|c|c|c|c|c|c|c|}
\hline \multirow[t]{2}{*}{ Run } & \multicolumn{3}{|c|}{ Input parameters } & \multicolumn{3}{|c|}{ Predicted response values } & \multicolumn{3}{|c|}{ Actual response values } & \multicolumn{3}{|c|}{ Percentage error $(\%)$} \\
\hline & Current (A) & Voltage (V) & Pulse (mu) & $S_{\mathrm{R}}(\mu \mathrm{m})$ & $K_{\mathrm{W}}(\mathrm{mm})$ & $C_{\mathrm{S}}(\mathrm{mm} / \mathrm{min})$ & $S_{\mathrm{R}}(\mu \mathrm{m})$ & $K_{\mathrm{W}}(\mathrm{mm})$ & $C_{\mathrm{S}}(\mathrm{mm} / \mathrm{min})$ & $S_{\mathrm{R}}$ & $K_{\mathrm{W}}$ & $C_{\mathrm{S}}$ \\
\hline 1 & 3 & 84 & 10 & 5.8 & 0.31 & 5.9 & 5.7 & 0.30 & 5.7 & 1.72 & 3.20 & 3.38 \\
\hline 2 & 4 & 75 & 20 & 5.2 & 0.34 & 3.0 & 5.0 & 0.33 & 2.9 & 3.84 & 2.94 & 3.33 \\
\hline 3 & 5 & 80 & 15 & 9.7 & 0.39 & 4.3 & 9.4 & 0.38 & 4.2 & 3.09 & 2.56 & 2.32 \\
\hline 4 & 3 & 75 & 20 & 5.2 & 0.31 & 2.8 & 5.0 & 0.30 & 2.7 & 3.84 & 3.22 & 3.57 \\
\hline
\end{tabular}

precisely predict the values of $S_{\mathrm{R}}, K_{\mathrm{W}}$ and $C_{\mathrm{S}}$ with an average prediction error of $3.15 \%$. It has already been cited in literature that the accuracy of a proposed model is justified if its prediction error is lesser than 5\% [53]. Thus, the accuracy of these models is authenticated.

Percentage error $=\left|\frac{\text { actual value- } \text { - predicted value }}{\text { predicted value }}\right| \times 100$

\subsection{Multi-objective genetic algorithm}

Genetic algorithm is a soft computing technique used for the optimization based on the natural process of gene selection. The algorithm is based on the survival of the fittest; only the best individual has the high probability of survival up to the next generation. For more than one objective function, the multi-objective genetic algorithm is used to optimize all objectives simultaneously [54]. Most of the time, the objectives have conflicting natures; increasing one function decreases the others. For such types of problems, the multi-objective genetic algorithm (MOGA) is used [38]. The formulated problem of MOGA generally consists of a number of equality and inequality constraints with the number of objective functions. A precise solution that optimizes each objective function simultaneously is practically impossible [55]. Therefore, a set of solutions exists that satisfies the multi-objective problems. Each set provides acceptable solutions to the objectives without being influenced by other solutions. In the case of assigning fitness to each solution, MOGA is distinct from the conventional genetic algorithm. Domination of each solution is checked first in MOGA. For general solution $i$, the rank of the solution is equal to the number of solutions $n i$ plus one that dominates solution $i$ is assigned as in given Eq. 6 below.

$R_{i}=1+n i$

It is observed that the cutting speed needs to be maximized while kerf width and surface roughness need to be minimized. When cutting speed increases, surface finish deteriorates, and kerf width increases. It can be seen that getting a highly desired value of one response affects others as well in the opposite manner. Thus, the conflicting nature of responses requires a single set of variables to produce the most optimized and desirable results. To achieve the highest cutting speed while controlling minimum surface roughness and kerf width, multi-
Fig. 13 Comparison of actual and predicted response values of confirmatory trial runs

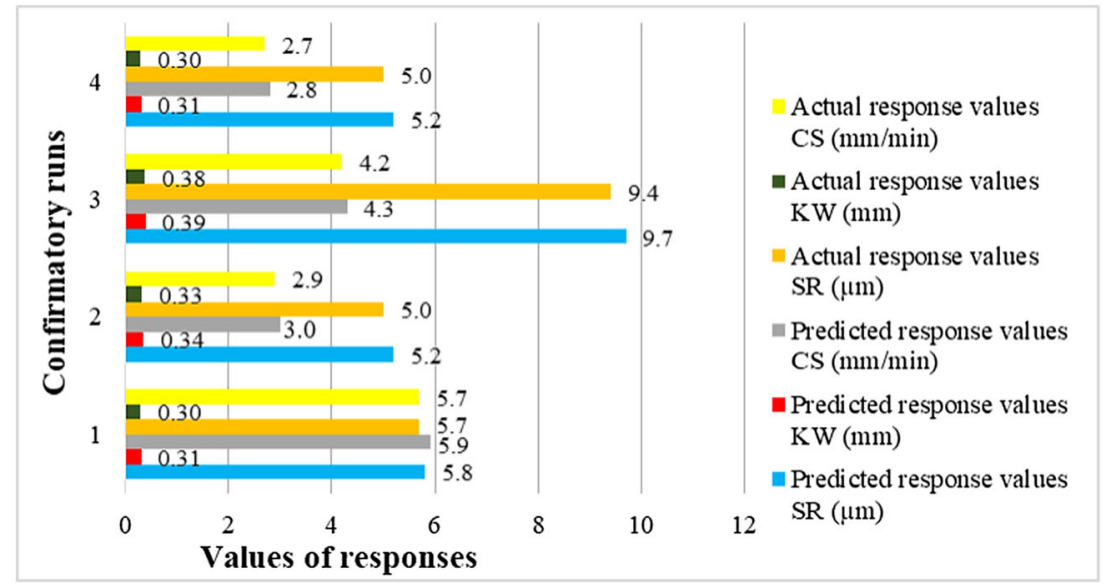


Table 5 MOGA optimal solutions

\begin{tabular}{lllllll}
\hline Sr. No & Current $(\mathrm{A})$ & Voltage $(\mathrm{V})$ & Pulse $(\mathrm{mu})$ & $S_{\mathrm{R}}(\mu \mathrm{m})$ & $K_{\mathrm{W}}(\mathrm{mm})$ & $C_{\mathrm{S}}(\mathrm{mm} / \mathrm{min})$ \\
\hline 1 & 3.7838445 & 75.489386 & 19.842339 & 5.2722095 & 0.3353988 & 3.0139298 \\
2 & 4.879995 & 79.444331 & 10.008338 & 7.3112663 & 0.362451 & 6.1383874 \\
3 & 4.224755 & 75.254455 & 19.84324 & 5.4960946 & 0.3515631 & 3.1124783 \\
4 & 3.0022605 & 75.022304 & 19.998166 & 5.108135 & 0.3121851 & 2.8269044 \\
5 & 3.6685061 & 75.430837 & 19.903408 & 5.1727031 & 0.3313182 & 2.9810443 \\
6 & 3.3816057 & 75.028954 & 19.999631 & 4.9882036 & 0.3215173 & 2.8931731 \\
7 & 4.9968205 & 77.93523 & 10.01376 & 7.5061488 & 0.3663244 & 6.1701528 \\
8 & 4.4281068 & 78.809916 & 10.016403 & 6.7483497 & 0.3463892 & 6.0409064 \\
9 & 3.5259866 & 80.853957 & 10.001243 & 6.016364 & 0.3242196 & 5.9294358 \\
10 & 4.3879401 & 75.227776 & 19.843703 & 5.6483068 & 0.3585166 & 3.1571893 \\
11 & 4.9995764 & 78.121491 & 10.00032 & 7.4968882 & 0.3665073 & 6.177393 \\
12 & 3.1869968 & 84.176266 & 10.005202 & 5.8035266 & 0.3154325 & 5.8926282 \\
13 & 3.8316642 & 82.18618 & 10.004476 & 6.1168661 & 0.3293056 & 5.9475069 \\
14 & 4.7351236 & 80.530645 & 10.000077 & 7.1188844 & 0.3570285 & 6.1007544 \\
15 & 4.9882278 & 79.050151 & 10.005161 & 7.4774937 & 0.3666082 & 6.1684171 \\
16 & 4.608096 & 80.468012 & 10.010046 & 6.9320193 & 0.3525024 & 6.0715807 \\
17 & 4.0452961 & 80.324661 & 10.00644 & 6.3162018 & 0.3355016 & 5.9825336 \\
18 & 3.0000001 & 84.99999 & 10.000001 & 5.7750002 & 0.31183 & 5.8849998 \\
\hline
\end{tabular}

objective optimization of input parameters was performed using MOGA. It is an evolutionary algorithm inspired by biological evolution used to evolve computer programs, either mathematical models or logical expression-based functions. It is based on biological operations such as reproduction, crossover, mutation and permutation, as shown in Fig. 1. Fitness function determines the quality of the gene and only best can take part in genetic operations, forming a new population of descendants. The overall mathematical model gets fitter until the reproduction is stopped. Hence, stopping criteria matters a lot on the quality of the final result. Hence, multiple independent runs are executed to get good enough and reliable results. The RSM-based mathematical models of surface roughness, kerf width and cutting speed are used as objective functions to perform optimization using MOGA in MATLAB 2019a within the range of following continuous parameters. The overall goal of the optimization is to minimize all the responses.

$$
\begin{gathered}
\text { Objective } \left._{1}=\text { Minimize }_{\text {SR }}\right) \\
\text { Objective }_{2}=\text { Minimize }(K W)_{\text {Objective }_{3}}=\text { Minimize }\left(\frac{1}{C s}\right)_{3} \leq I_{\mathrm{p}} \leq 5 \\
75 \leq V \leq 85 \\
10 \leq P \leq 20
\end{gathered}
$$

The MOGA was executed considering the following parameters: population 200, crossover rate $80 \%$ and mutation rate $5 \%$. To optimize all the responses, a number of combinations of crossover and mutation are tried while this combination is found suitable in enhancing the traits of MOGA. High crossover and low mutation ensure in maintaining optimal fits and helping in not losing genetic traits while flipping, respectively. MOGA resulted in 18 optimal solutions, as mentioned in Table 5. The surface
Fig. 14 Surface plot for all responses against optimal solutions

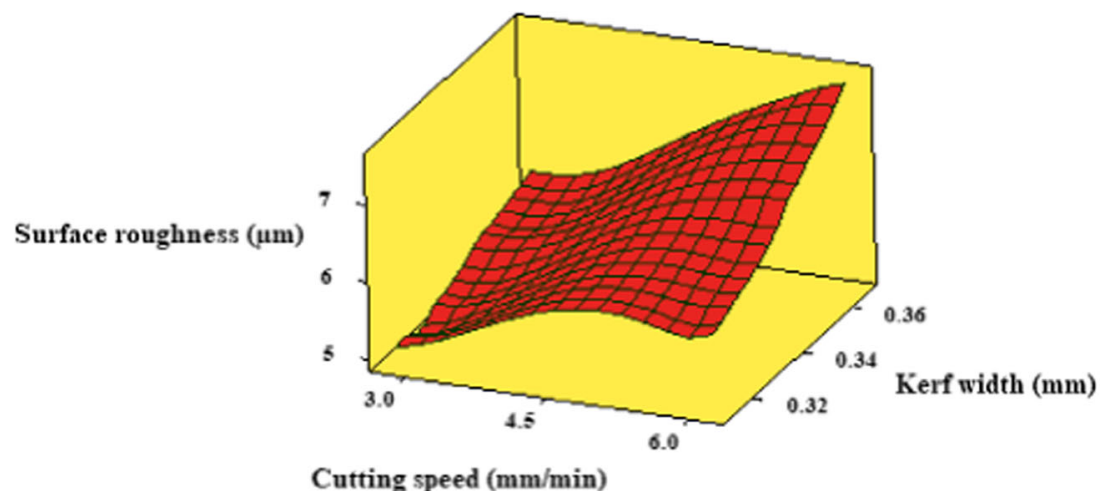


Table 6 Confirmatory trial result for MOGA optimal solution

\begin{tabular}{|c|c|c|c|c|c|c|c|c|c|c|c|}
\hline \multicolumn{3}{|c|}{ Optimal input parameters } & \multicolumn{3}{|c|}{ Optimal responses } & \multicolumn{3}{|c|}{ Confirmatory results } & \multicolumn{3}{|c|}{ Error $(\%)$} \\
\hline Current (A) & Voltage (V) & Pulse (mu) & $S_{\mathrm{R}}(\mu \mathrm{m})$ & $K_{\mathrm{W}}(\mathrm{mm})$ & $C_{\mathrm{S}}(\mathrm{mm} / \mathrm{min})$ & $S_{\mathrm{R}}(\mu \mathrm{m})$ & $K_{\mathrm{W}}(\mathrm{mm})$ & $C_{\mathrm{S}}(\mathrm{mm} / \mathrm{min})$ & $S_{\mathrm{R}}$ & $K_{\mathrm{W}}$ & $C_{\mathrm{S}}$ \\
\hline \multirow[t]{3}{*}{3} & \multirow[t]{3}{*}{84.999} & \multirow[t]{3}{*}{10} & \multirow[t]{3}{*}{5.775} & \multirow[t]{3}{*}{0.311} & \multirow[t]{3}{*}{5.885} & 5.92 & 0.317 & 5.884 & 2.51 & 1.93 & 0.76 \\
\hline & & & & & & 5.84 & 0.315 & 5.883 & 1.13 & 1.29 & 2.29 \\
\hline & & & & & & 5.89 & 0.314 & 5.886 & 1.99 & 0.96 & 1.78 \\
\hline Average & & & & & & 5.883 & 0.3153 & 5.79 & 1.88 & 1.39 & 1.61 \\
\hline
\end{tabular}

plot of all the responses against optimal solutions is shown in Fig. 14. With the increase in cutting speed (achieving objective ${ }_{3}$ ) increases surface roughness and kerf width (showing un-attainment of objective $_{1}$ and objective $_{2}$ ). Higher discharge energy increases the machining speed due to increased area of melt pool, on the other hand, deteriorates surface characteristics in terms of deeper and wider craters increasing work roughness. Similarly, the kerf width increases due to higher spark energy transfer, as shown in Fig. 14. This shows the conflicting nature of objectives (one maximization, rest minimization).

The confirmation trials were conducted for verification purposes of the optimal combination of input parameters. The optimal test was repeated three times, and the values are reported in Table 6. It is cleared from the confirmatory test results that the average percentage error was less than $2 \%$, which confirms the adequacy of the best optimal solution of MOGA. Since the objective were to minimize the $S_{\mathrm{R}}$ and $K_{\mathrm{W}}$ and maximize the $C_{\mathrm{S}}$, so, the best optimal solution obtained from MOGA is compared with RSM-based experiment results of run numbers 7, 11 and 14, respectively (Table 7). Minimum $K_{\mathrm{W}}$ and $S_{\mathrm{R}}$ and maximum $C_{\mathrm{S}}$ were achieved at conditions of run numbers 7, 11 and 14. Single optimal input parameter condition was only attained by MOGA at which all the responses were optimized, as illustrated in Table 7

\section{Conclusions}

In this research, the potential of the WEDM process in order to detect a suitable machining window for newly developed A16061-7.5\% SiC composite was systematically investigated. The composite was developed via squeeze casting process. It exhibits promising mechanical attributes because of the reinforcement of $7.5 \% \mathrm{SiC}$ in the Al-substrate. The potential of using an optimized WEDM has been comprehensively investigated, for the machinability Al6061-7.5\% SiC composite, which has not been explicitly studied so far. The cutting performance was assessed in terms of machinability measure like surface finish $\left(S_{\mathrm{R}}\right)$, cutting speed $\left(C_{\mathrm{S}}\right)$ and kerf width $\left(K_{\mathrm{W}}\right)$ considering current, voltage and pulse as input variables under RSM Box-Behnken design. The experimental results have been deeply analyzed using different statistical analyses such as ANOVA, surface plots and regression analyses. Furthermore, optical-microscopic and SEM analyses are carried out to explain the findings with physical evidence. Furthermore, multi-objective genetic algorithm was used for the development of optimal parametric combination. Based on the experimental outcomes and their respective discussion, following salient conclusions may be drawn:

1. Experimental results reveal that Al6061-7.5\% SiC composite has been successfully machined with a notably high

Table 7 Comparison of MOGA optimal solution with RSM-based results

\begin{tabular}{|c|c|c|c|c|c|c|}
\hline \multirow[t]{2}{*}{ Source } & \multicolumn{3}{|c|}{ Input parameters } & \multicolumn{3}{|c|}{ Responses } \\
\hline & Current (A) & Voltage (V) & Pulse (mu) & $S_{\mathrm{R}}(\mu \mathrm{m})$ & $K_{\mathrm{W}}(\mathrm{mm})$ & $C_{\mathrm{S}}(\mathrm{mm} / \mathrm{min})$ \\
\hline MOGA optimal solution & 3 & 84.999 & 10 & 5.775 & 0.311 & 5.885 \\
\hline Exp. run 7 & 3 & 80 & 20 & 6.28 & 0.316 & 3.24 \\
\hline Improvement (\%) & & & & $8.74 \%$ & $1.61 \%$ & $44.94 \%$ \\
\hline Exp. run 11 & 4 & 75 & 20 & 5.2 & 0.345 & 3.18 \\
\hline Improvement (\%) & & & & $-9.96 \%$ & $10.93 \%$ & $45.96 \%$ \\
\hline Exp. run 14 & 4 & 80 & 15 & 8.48 & 0.346 & 6.18 \\
\hline Improvement (\%) & & & & $46.84 \%$ & $11.25 \%$ & $-5.01 \%$ \\
\hline
\end{tabular}


cutting rate of $6 \mathrm{~mm} / \mathrm{min}$ using WEDM. The minimum value of surface roughness obtained during experimentation is $5.2 \mu \mathrm{m}$, whereas the minimum kerf width of $0.316 \mathrm{~mm}$ is realized.

2. Voltage has been noticed to be the most influential/ contributing parameter for controlling the $S_{\mathrm{R}}$ during WEDM of Al6061-7.5\% SiC composite having a percentage contribution of $25 \%$. Whereas for $C_{\mathrm{S}}$ and $K_{\mathrm{W}}$, pulse (having a percentage contribution of 90\%) and current (having a contribution of $84 \%$ ) are the major contributing control variables, respectively. It has also been revealed that the output variables are also significantly influenced by interaction and quadratic terms.

3. The surface finish of the machined Al6061-7.5\% SiC composite is improved at low values of voltage and current. The roughness magnitude achieved at the said settings is $33.3 \%$ lesser than that obtained at higher values of both parameters. The low magnitude of both current and voltage induces a smaller amount of discharge energy in the electrode-workpiece gap. SEM and optical microscopic analyses reveal that low discharge energy produces shallow craters. The size of the melted re-deposits and micro globules formed at such condition is also found small. Consequently, a good surface finish is realized. In the case of pulse, high value is providing smaller roughness because of the in-effective transfer of discharge energy from the electrode surface to the workpiece.

4. In the case of KW, smaller values of all the selected control parameters such as current, voltage and pulse yield narrower kerf width. The smaller values of the control parameters have reduced the kerf size up to $20 \%$. This happens because a lesser amount of current and voltage provides feebler spark discharge, and the energy of such discharge is efficiently transferred to the work surface at low pulse value. The low pulse value ensures that the width of the plasma channel to remain effective by keeping/maintaining the workpiece-electrode gap at a minimum. Therefore, a small amount of workpiece material is eroded from the target surface, yielding a narrow kerf width.

5. The cutting speed is observed to have a direct relationship with the spark strength/discharge energy. Higher values of both current and voltage resulted in powerful spark discharges that induce a strong penetrating heat flux in the target material. As a result, cutting speed is increased up to $5.94 \mathrm{~mm} / \mathrm{min}$ (approximately $32.3 \%$ rise in cutting rate). Contrarily, a smaller pulse value gives improved cutting speed because of the effective transfer of discharge energy.

6. Empirical models for the accurate prediction of the defined responses $\left(S_{\mathrm{R}}, K_{\mathrm{W}}\right.$ and $C_{\mathrm{S}}$ ) have been successfully formulated during the WEDM of newly developed Al6061-7.5\% SiC composite. Their prediction exactness has been validated through confirmatory trials. It is pertinent to mention that the average prediction error of these models comes out $3.15 \%$ during confirmation trials, which highlights the adequacy of the proposed models.

7. The multi-objective genetic algorithm provides the best optimal solution for all the three conflicting responses. The best combination of WEDM input parameters was found as current $=3 \mathrm{~A}$, voltage $=84.999 \mathrm{~V}$ and pulse $=$ $10 \mathrm{mu}$. This combination gives a minimum $S_{\mathrm{R}}$ of $5.775 \mu \mathrm{m}$ with a $K_{\mathrm{W}}$ of $0.3111 \mathrm{~mm}$ at a $C_{\mathrm{S}}$ of 5.885 $\mathrm{mm} / \mathrm{min}$. The optimal solution has been validated through confirmatory trials. Results of confirmatory trials depict that the average error between models' predicted and experimental values are very small, i.e. $1.8 \%, 1.39 \%$ and $1.61 \%$ for $S_{\mathrm{R}}, K_{\mathrm{W}}$ and $C_{\mathrm{S}}$, respectively. Furthermore, a comparison was made between MOGA-iterated optimal solution and RSM-based optimal solution. The comparisons' results evidently authenticate the supremacy of the MOGA-proposed optimal solution for the defined conflicting responses, i.e. $S_{\mathrm{R}}, K_{\mathrm{W}}$ and $C_{\mathrm{S}}$ as mentioned in Table 7.

Acknowledgements Researchers supporting project number (RSP-2020/ 145), King Saud University, Riyadh, Saudi Arabia.

Open Access This article is licensed under a Creative Commons Attribution 4.0 International License, which permits use, sharing, adaptation, distribution and reproduction in any medium or format, as long as you give appropriate credit to the original author(s) and the source, provide a link to the Creative Commons licence, and indicate if changes were made. The images or other third party material in this article are included in the article's Creative Commons licence, unless indicated otherwise in a credit line to the material. If material is not included in the article's Creative Commons licence and your intended use is not permitted by statutory regulation or exceeds the permitted use, you will need to obtain permission directly from the copyright holder. To view a copy of this licence, visit http://creativecommons.org/licenses/by/4.0/.

\section{References}

1. Dhanashekar M, Kumar VS (2014) Squeeze casting of aluminium metal matrix composites-an overview. Procedia Eng 97:412-420

2. Rui-song J, Wen-hu W, Guo-dong S, Zeng-qiang W (2016) Experimental investigation on machinability of in situ formed TiB2 particles reinforced Al MMCs. J Manuf Process 23:249-257

3. Bhushan RK, Kumar S (2011) Influence of SiC particles distribution and their weight percentage on $7075 \mathrm{Al}$ alloy. J Mater Eng Perform 20(2):317-323

4. Mousavian RT, Khosroshahi RA, Yazdani S, Brabazon D, Boostani A (2016) Fabrication of aluminum matrix composites reinforced with nano-to micrometer-sized $\mathrm{SiC}$ particles. Mater Des 89:58-70

5. Kala H, Mer K, Kumar S (2014) A review on mechanical and tribological behaviors of stir cast aluminum matrix composites. Procedia Mater Sci 6:1951-1960 
6. Arulraj M, Palani P (2018) Parametric optimization for improving impact strength of squeeze cast of hybrid metal matrix (LM24-SiC p-coconut shell ash) composite. J Braz Soc Mech Sci Eng 40(1):2

7. Sidhu SS, Batish A, Kumar S (2014) Study of surface properties in particulate-reinforced metal matrix composites (MMCs) using powder-mixed electrical discharge machining (EDM). Mater Manuf Process 29(1):46-52

8. Mosleh-Shirazi S, Hua G, Akhlaghi F, Yan X, Li D (2015) Interfacial valence electron localization and the corrosion resistance of Al-SiC nanocomposite. Sci Rep 5:18154

9. Sarfraz MH, Jahanzaib M, Ahmed W, Hussain S (2019) Multiresponse parametric optimization of squeeze casting process for fabricating Al 6061-SiC composite. Int J Adv Manuf Technol 102(1-4):759-773

10. Dey A, Pandey KM (2018) Selection of optimal processing condition during WEDM of compocasted AA6061/cenosphere AMCs based on grey-based hybrid approach. Mater Manuf Process 33(14):1549-1558

11. Das S, Joshi SN (2020) Estimation of wire strength based on residual stresses induced during wire electric discharge machining. J Manuf Process 53:406-419

12. Azam M, Jahanzaib M, Abbasi JA, Wasim A (2016) Modeling of cutting speed (CS) for HSLA steel in wire electrical discharge machining (WEDM) using moly wire. J Chin Inst Eng 39(7):802-808

13. Fard RK, Afza RA, Teimouri R (2013) Experimental investigation, intelligent modeling and multi-characteristics optimization of dry WEDM process of $\mathrm{Al}-\mathrm{SiC}$ metal matrix composite. J Manuf Process 15(4):483-494

14. Ishfaq K, Mufti NA, Ahmed N, Mughal MP, Saleem MQ (2018) An investigation of surface roughness and parametric optimization during wire electric discharge machining of cladded material. Int $\mathrm{J}$ Adv Manuf Technol 97(9):4065-4079

15. Abyar H, Abdullah A, Akbarzadeh A (2018) Analyzing wire deflection errors of WEDM process on small arced corners. J Manuf Process 36:216-223

16. Gopalakannan S, Senthilvelan T, Ranganathan S (2012) Modeling and optimization of EDM process parameters on machining of $\mathrm{Al}$ 7075-B4C MMC using RSM. Procedia Eng 38:685-690

17. Bobbili R, Madhu V, Gogia AK (2015) Modelling and analysis of material removal rate and surface roughness in wire-cut EDM of armour materials. Eng Sci Technol Int J 18(4):664-668

18. Chaudhari R, Vora JJ, Patel V, López de Lacalle L, Parikh D (2020) Surface analysis of wire-electrical-discharge-machining-processed shape-memory alloys. Materials 13(3):530

19. Mandal A, Dixit AR, Chattopadhyaya S, Paramanik A, Hloch S, Królczyk G (2017) Improvement of surface integrity of Nimonic C 263 super alloy produced by WEDM through various postprocessing techniques. Int J Adv Manuf Technol 93(1-4):433-443

20. Sivaprakasam P, Hariharan P, Gowri S (2013) Optimization of micro-WEDM process of aluminum matrix composite (A413B4C): a response surface approach. Mater Manuf Process 28(12): $1340-1347$

21. Abbasi JA, Jahanzaib M, Azam M, Hussain S, Wasim A, Abbas M (2017) Effects of wire-cut EDM process parameters on surface roughness of HSLA steel. Int J Adv Manuf Technol 91(5-8): $1867-1878$

22. Nawaz Y, Maqsood S, Naeem K, Nawaz R, Omair M, Habib T (2020) Parametric optimization of material removal rate, surface roughness, and kerf width in high-speed wire electric discharge machining (HS-WEDM) of DC53 die steel. Int J Adv Manuf Technol 107(7-8):3231-3245

23. Suresh S, Sudhakara D (2019) Investigations on wire electric discharge machining and mechanical behavior of Al 7075/nano-SiC composites. J Inst Eng (India) Ser D 100(2):217-227
24. Rao TB, Krishna AG (2014) Selection of optimal process parameters in WEDM while machining Al7075/SiCp metal matrix composites. Int J Adv Manuf Technol 73(1-4):299-314

25. Prakash JU, Juliyana SJ, Pallavi P, Moorthy T (2018) Optimization of wire EDM process parameters for machining hybrid composites (356/B4C/Fly ash) using Taguchi technique. Mater Today Proc 5(2):7275-7283

26. Dey A, Pandey KM (2018) Wire electrical discharge machining characteristics of AA6061/cenosphere as-cast aluminum matrix composites. Mater Manuf Process 33(12):1346-1353

27. Karabulut Ș, Karakoç H, Çitak R (2017) Effect of the B4C rein- 894 forcement ratio on surface roughness of A16061 based metal matrix 895 composite in wire-EDM machining. In: 2017 8th International 896 Conference on Mechanical and Aerospace Engineering (ICMAE). 897 IEEE, pp 812-815. https://doi.org/10.1109/ ICMAE.2017.8038755

28. Tarng Y, Ma S, Chung L (1995) Determination of optimal cutting parameters in wire electrical discharge machining. Int J Mach Tools Manuf 35(12):1693-1701

29. Geng X, Chi G, Wang Y, Wang Z (2014) Study on microrotating structure using microwire electrical discharge machining. Mater Manuf Process 29(3):274-280

30. Azam M, Jahanzaib M, Abbasi JA, Abbas M, Wasim A, Hussain S (2016) Parametric analysis of recast layer formation in wire-cut EDM of HSLA steel. Int J Adv Manuf Technol 87(1-4):713-722

31. Tosun N, Cogun C, Tosun G (2004) A study on kerf and material removal rate in wire electrical discharge machining based on Taguchi method. J Mater Process Technol 152(3):316-322

32. Tahir W, Jahanzaib M, Ahmad W, Hussain S (2019) Surface morphology evaluation of hardened HSLA steel using cryogenictreated brass wire in WEDM process. Int J Adv Manuf Technol 104(9-12):4445-4455

33. Lin J, Lin C (2005) The use of grey-fuzzy logic for the optimization of the manufacturing process. J Mater Process Technol 160(1):9-14

34. Soepangkat BOP, Pramujati B (2013) Optimization of Surface Roughness and Recast Layer Thickness in the Wire-EDM Process of AISI D2 Tool Steel Using Taguchi-Grey-Fuzzy. Applied Mechanics and Materials, 393, 21-28. https://doi.org/10. 4028/www.scientific.net/amm.393.21

35. Sanchez JA, Plaza S, Lopez de Lacalle L, Lamikiz A (2006) Computer simulation of wire-EDM taper-cutting. Int J Comput Integr Manuf 19(7):727-735

36. Dewangan S, Gangopadhyay S, Biswas C (2015) Study of surface integrity and dimensional accuracy in EDM using Fuzzy TOPSIS and sensitivity analysis. Measurement 63:364-376

37. Jafarian F (2020) Electro discharge machining of Inconel 718 alloy and process optimization. Mater Manuf Process 35(1):95-103

38. Biswas MS, Mandal K, Sarkar S (2020) MOGA approach in WEDM of advanced aluminium alloy. Mater Today Proc 26(2): 887-890

39. Zolpakar NA, Lodhi SS, Pathak S, Sharma MA (2020) Application of multi-objective genetic algorithm (MOGA) optimization in machining processes. In: Optimization of Manufacturing Processes. Springer Series in Advanced Manufacturing. Springer, Cham, pp 185-199

40. Raza MH, Wasim A, Ali MA, Hussain S, Jahanzaib M (2018) Investigating the effects of different electrodes on A16061-SiC7.5 wt \% during electric discharge machining. Int J Adv Manuf Technol 99(9-12):3017-3034

41. Demir H, Gündüz S (2009) The effects of aging on machinability of 6061 aluminium alloy. Mater Des 30(5):1480-1483

42. Ali MA, Jahanzaib M, Wasim A, Hussain S, Anjum NA (2018) Evaluating the effects of as-casted and aged overcasting of Al-Al joints. Int J Adv Manuf Technol 96(1-4):1377-1392

43. Ishfaq K, Ahmed N, Mufti NA, Pervaiz S (2019) Exploring the contribution of unconventional parameters on spark gap formation 
and its minimization during WEDM of layered composite. Int J Adv Manuf Technol 102(5-8):1659-1669

44. Umar Farooq M, Pervez Mughal M, Ahmed N, Ahmad Mufti N, Al-Ahmari AM, He Y (2020) On the investigation of surface integrity of Ti6A14V ELI using Si-mixed electric discharge machining. Materials 13(7):1549

45. Kanlayasiri K, Boonmung S (2007) An investigation on effects of wire-EDM machining parameters on surface roughness of newly developed DC53 die steel. J Mater Process Technol 187:26-29

46. Prasad D, Krishna AG (2015) Empirical modeling and optimization of kerf and wire wear ratio in wire electrical discharge machining. Int J Adv Manuf Technol 77(1-4):427-441

47. Ishfaq K, Ahmad N, Jawad M, Ali MA, Al-Ahmari AM (2019) Evaluating material's interaction in wire electrical discharge machining of stainless steel (304) for simultaneous optimization of conflicting responses. Materials 12(12):1940

48. Chu X, Zeng X, Zhuang W, Zhou W, Quan X, Fu T (2019) Vibration assisted high-speed wire electric discharge machining for machining surface microgrooves. J Manuf Process 44:418-426

49. Muniappan A, Jayakumar V, Ajithkumar R, Veerabhadra S, Prasanna R (2019) Optimization of WEDM process parameters for cutting speed using Taguchi technique. Mater Today Proc 18: 332-341

50. Ikram A, Mufti NA, Saleem MQ, Khan AR (2013) Parametric optimization for surface roughness, kerf and MRR in wire electrical discharge machining (WEDM) using Taguchi design of experiment. J Mech Sci Technol 27(7):2133-2141

51. Ali MA, Ishfaq K, Raza MH, Farooq MU, Mufti NA, Pruncu CI (2020) Mechanical characterization of aged AA2026-AA2026 overcast joints fabricated by squeeze casting. Int J Adv Manuf Technol 107(7-8):3277-3297

52. Ali MA, Ishfaq K, Jawad M (2019) Evaluation of surface quality and mechanical properties of squeeze casted AA2026 aluminum alloy using response surface methodology. Int J Adv Manuf Technol 103(9-12):4041-4054

53. Ishfaq K, Ali MA, Ahmad N, Zahoor S, Al-Ahmari AM, Hafeez F (2020) Modelling the mechanical attributes (roughness, strength, and hardness) of Al-alloy A356 during sand casting. Materials 13(3):598

54. Han X, Zhang Z (2019) topological optimization of phononic crystal thin plate by a Genetic Algorithm. Sci Rep 9(1):1-13

55. Wojciechowski S, Chwalczuk T, Twardowski P, Krolczyk GM (2015) Modeling of cutter displacements during ball end milling of inclined surfaces. Arch Civ Mech Eng 15(4):798-805

Publisher's note Springer Nature remains neutral with regard to jurisdictional claims in published maps and institutional affiliations. 